Andrews University

Digital Commons @ Andrews University

2020

\title{
Mother-Infant Attachment: Path Analysis of the Predictive Role of Trauma Therapy and Select Demographics on Mother's Cognitive Responses
}

Nicole D. Knapp

Follow this and additional works at: https://digitalcommons.andrews.edu/dissertations

\section{Recommended Citation}

Knapp, Nicole D., "Mother-Infant Attachment: Path Analysis of the Predictive Role of Trauma Therapy and Select Demographics on Mother's Cognitive Responses" (2020). Dissertations. 1727.

https://digitalcommons.andrews.edu/dissertations/1727

https://dx.doi.org/10.32597/dissertations/1727

This Dissertation is brought to you for free and open access by the Graduate Research at Digital Commons @ Andrews University. It has been accepted for inclusion in Dissertations by an authorized administrator of Digital Commons@ Andrews University. For more information, please contact repository@andrews.edu. 


\begin{abstract}
MOTHER-INFANT ATTACHMENT: PATH ANALYSIS OF THE PREDICTIVE ROLE OF TRAUMA THERAPY AND SELECT DEMOGRAPHICS ON MOTHER'S COGNITIVE RESPONSES
\end{abstract}

by

Nicole D. Knapp

Chair: Dennis Waite, Ed.D. 


\title{
ABSTRACT OF GRADUATE STUDENT RESEARCH
}

\author{
Dissertation \\ Andrews University \\ College of Education \& International Services
}

Title: Mother-infant Attachment: Path Analysis of the Predictive Role of Trauma Therapy and Select Demographics on Mother's Cognitive Responses

Name of researcher: Nicole D. Knapp

Name and degree of faculty chair: Dennis Waite, Ed.D.

Date completed: June 2020

\section{Problem}

The best outcome for attachment when an infant is born would be a secure attachment, but this is not always the case. Insecure attachments are likely to be formed when the mother has experienced domestic violence given the right environment (HuthBocks et al., 2011; Theran et al., 2005). A previous study showed that changes to attachment due to postnatal intervention are based on external behaviors rather than internal though processes (Theran et al., 2005). Because of this, the purpose of this study is to compare therapy categories and each of the observable attachment factors. 


\section{Method}

Participants completed a survey which measured the tolerance, acceptance, pleasure in proximity, and competence as a parent in regard to the mother's response to her child(ren) ages zero to six months old, as well demographic information. Data was analyzed using a one-way multivariate analysis of variance (MANOVA), a one-way analysis of variance (ANOVA), post hoc tests, and a path analysis to answer two main research questions and five sub-questions.

\section{Results}

The MANOVA results showed a marginally significant difference among the trauma therapy categories on the dependent variables. Subsequent ANOVA results showed that, individually, trauma therapy had a significant effect on tolerance, pleasure in proximity, and competence as a parent. Bonferroni post hoc analysis showed that not attending therapy significantly differs from attending group therapy in regard to competence as a parent.

The hypothesized model was a good fit for the data. This model indicated a weak statistically significant direct effect of childhood abuse on trauma therapy. Race, childhood abuse, and support system all had weak statistically significant direct effect on ATT and trauma therapy had a weak moderately significant direct effect on ATT.

\section{Conclusion}

This study was designed to help understand if various types of trauma therapy could be effective in the formation of a more secure attachment between mother and infant when the mother has had a history of domestic violence. This study also looked to 
understand if various demographic factors have an effect on the attendance of trauma therapy or on ATT, either directly or as mediated through trauma therapy. Results have indicated that when looking at maternal attachment responses, it may be more beneficial to look at the individual types of trauma therapy and areas of attachment rather than at trauma therapy and attachment as wholes. In regard to demographic factors, there were weak significant direct effects found for both trauma therapy and ATT. This study also offers various implications for future research and professional practice. 


\author{
Andrews University \\ College of Education \& International Services
}

\title{
MOTHER-INFANT ATTACHMENT: PATH ANALYSIS OF THE PREDICTIVE ROLE OF TRAUMA THERAPY AND SELECT DEMOGRAPHICS ON MOTHER'S COGNITIVE RESPONSES
}

\author{
A Dissertation \\ Presented in Partial Fulfillment \\ of the Requirements for the Degree \\ Doctor of Philosophy
}

by

Nicole D. Knapp

June 2020 
CCopyright by Nicole D. Knapp 2020 All Rights Reserved 


\title{
MOTHER-INFANT ATTACHMENT: PATH ANALYSIS OF THE PREDICTIVE ROLE OF TRAUMA THERAPY AND SELECT DEMOGRAPHICS ON MOTHER'S COGNITIVE RESPONSES
}

\author{
A dissertation \\ presented in partial fulfillment \\ of the requirements for the degree \\ Doctor of Philosophy
}

by

Nicole D. Knapp

APPROVAL BY THE COMMITTEE:

Chair: Dennis Waite

Member: Tevni Grajales

External: Melissa Ponce-Rodas

Member: Nancy Carbonell
Dean, College of Education \& International Services Alayne Thorpe

Date approved 


\section{TABLE OF CONTENTS}

LIST OF ILLUSTRATIONS ...................................................................... vi

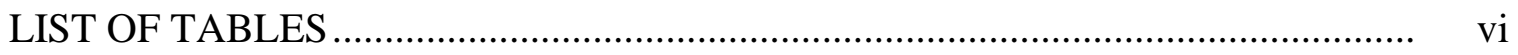

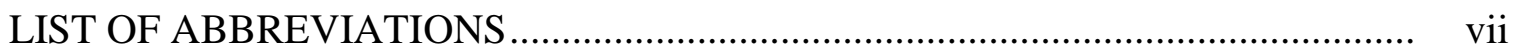

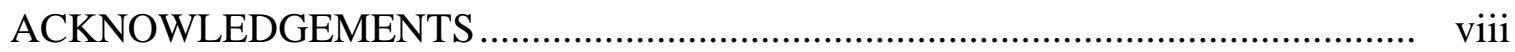

Chapter

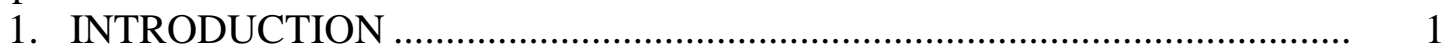

Background of the Problem .......................................................................

Statement of the Problem...................................................................... 2

Purpose of the Study ............................................................................ 3

Research Questions .............................................................................. 3

Significance of the Study ........................................................................ 5

Conceptual Framework …………………………….............................. 5

Definition of Terms............................................................................... 7

Limitations and Delimitations.................................................................... 8

Organization of Study .................................................................... 9

2. LITERATURE REVIEW ………………………….......................... 10

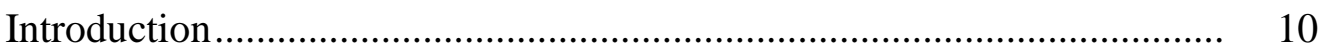

Attachment Theory ................................................................................ 11

Mother-Child Attachment................................................................ 12

Adult Attachment....................................................................... 14

Trauma Theory .......................................................................... 14

Trauma Theory and Hormone Activation........................................... 15

Trauma Theory and the Brain ........................................................ 16

Domestic Violence............................................................................. 16

Types of Domestic Violence............................................................. 17

Factors Influencing Domestic Violence............................................... 17

Beliefs and Attitudes Regarding Domestic Violence .......................... 19

Trauma Therapy and Domestic Violence ................................................. 20

Mother-Child Attachment and Domestic Violence ................................... 23

Influences on Perceived Maternal Capability ....................................... 23

Mother's Childhood …….......................................................... 23 
Impact of Domestic Violence ......................................................... 24

Maternal Views of Child................................................................. 25

Mother-Infant Attachment ............................................................ 26

Mother-Child Attachment............................................................... 27

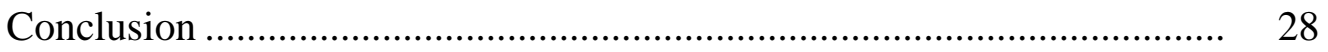

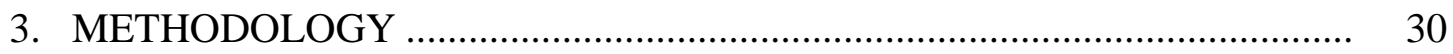

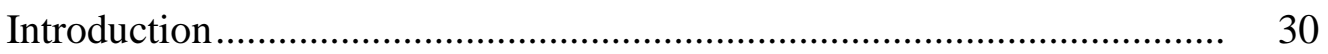

Type of Study ............................................................................... 30

Population and Sample ....................................................................... 31

Hypothesis............................................................................ 31

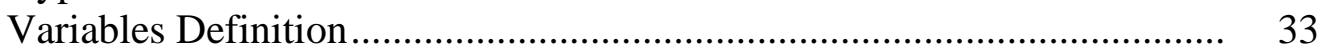

The Maternal Postnatal Attachment Scale .................................................. 34

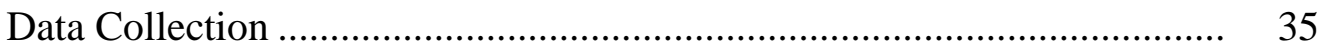

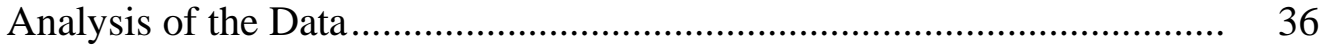

Summary …….......................................................................... 37

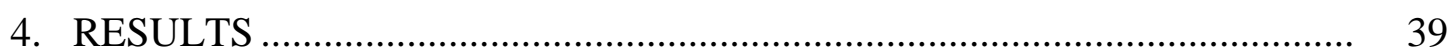

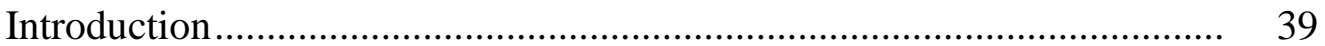

Description of Sample...................................................................... $\quad 39$

Observed Variables Description .............................................................. $\quad 40$

Zero-Order Correlations......................................................................... 40

Results by Question ........................................................................ 42

Question 1 .................................................................... 44

Question 2: Hypothesis Testing .......................................................... 44

Intercorrelations Among Variables ................................................ 46

Summary of Findings ......................................................................... 48

5. SUMMARY, DISCUSSION, AND IMPLICATIONS ..................................... 49

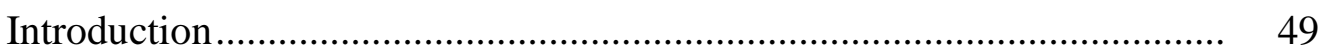

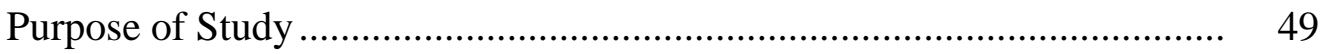

Summary of Literature Review.......................................................... $\quad 50$

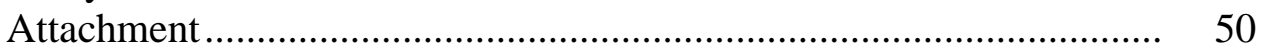

Trauma Theory, Domestic Violence, and Trauma Therapy ................ 51

Mother-Infant Attachment and Domestic Violence............................. 52

Methodology .................................................................................. 53

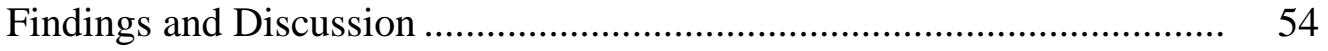

Sample Demographics ................................................................. 54

Research Question 1 .................................................................. 54

Research Question 2 ............................................................... 56

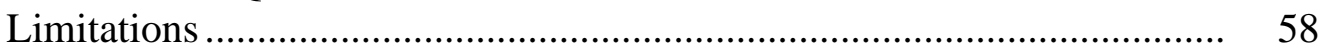

Recommendations .................................................................... 58

Recommendations for Future Research ............................................ 59 
Recommendations for Practice ................................................. 59

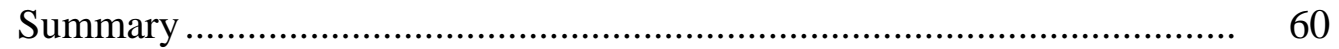

Appendix

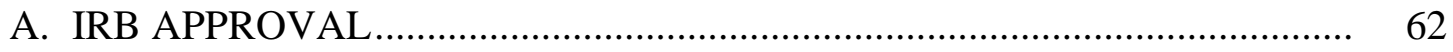

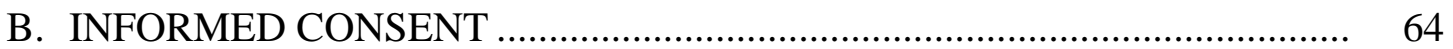

C. DEMOGRAPHIC QUESTIONNAIRE \& MPAS ........................................ 67

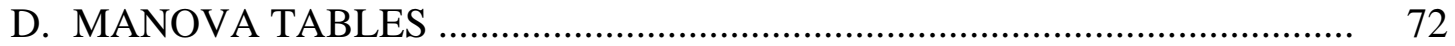

E. PATH ANALYSIS TABLES ............................................................... 78

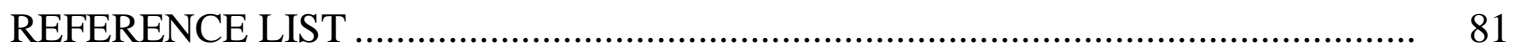

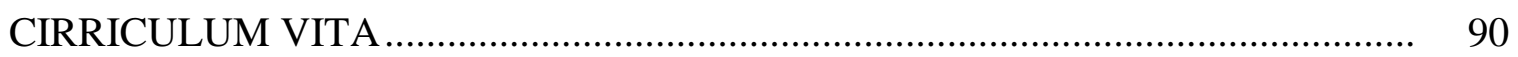




\section{LIST OF ILLUSTATIONS}

1. Hypothesized Model ................................................................................... 4

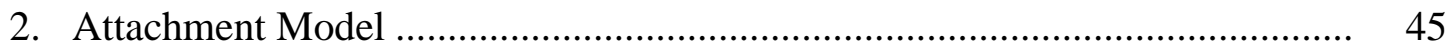

\section{LIST OF TABLES}

1. Demographic Information......................................................................... 41

2. Observed Variable Statistics ........................................................................ 42

3. Zero-Order Correlation …………………………………………………....

4. Means and Standard Deviations for Attachment Factors by Trauma Therapy Categories …………………………………............................. 45

5. Summary of Casual Effects of the Attachment Model ..................................... 47

6. Raw and Standardized Coefficients for the Attachment Model ....................... 47 


\section{LIST OF ABBREVIATIONS}

\begin{tabular}{ll} 
AMOS & Analysis of a Moment Structures \\
ANOVA & One-way Analysis of Variance \\
APA & American Psychological Association \\
CTT-BW & Comparative Fit Index \\
DOJ & Cognitive Trauma Therapy for Battered Women \\
DV & Department of Justice \\
GFI & Domestic Violence \\
IA & Goodness of Fit Index \\
MANOVA & Insecure Attachment \\
MPAS & One-way Multivariate Analysis of Variance \\
NDVH & The Maternal Postnatal Attachment Scale \\
NFI & National Domestic Violence Hotline \\
PTSD & Normed Fit Index \\
RMSEA & Post-Traumatic Stress Disorder \\
SA & Root Mean Square Error of Approximation \\
SPSS & Secure Attachment \\
\hline
\end{tabular}




\section{ACKNOWLEDGEMENTS}

This has been a process and there are some people whom I would not have been able to do this without. First and foremost, I would like to acknowledge and give endless thanks to my son, Brayden. Without his support, understanding, comedy, and, at times, not so subtle annoyance with my whining, I would have not been able to make it through my courses and especially through the writing of my dissertation. To my mom who has given me her full support every step of the way, even when she didn't quite understand what she was supporting. To Kati for continually asking me questions and pushing me to think about every detail of this research. And lastly, to Hadiya who went through this process with me, kept me at a relatively sane level when things weren't going how I planned, and celebrated all of the little victories with me along the way.

Lastly, I would like to thank my committee: Dr. Dennis Waite, Dr. Nancy Carbonell, and Dr. Tevni Grajales. Without your guidance, encouragement, understanding, and patience, this would not have been possible. 


\section{CHAPTER 1}

\section{INTRODUCTION}

\section{Background of the Problem}

In an article written for PewResearch, Livingston and Bialik (2018) reported that on average, mothers who were also in the labor force in 2016 were dedicating about 14 hours a week to childcare. This was about six hours more than the fathers during that same year and about four more hours than what was reported by working mothers in 1965. This is in addition to the estimated $27 \%$ of all mothers who are stay-at-home moms (Livingston, 2018). With millions of individuals experiencing domestic violence (DV) each year (Centers for Disease Control and Prevention, 2017), it could be presumed that many of those, whether they be working or stay-at-home mothers, whom are the primary caregivers, are experiencing or have experienced some form of DV. While previous studies have already examined the impact of DV on the mother's ability to form a secure attachment (SA) with their child, this study looked to ways for improving the attachment that was formed by examining the impact in which trauma therapy conducted before or during pregnancy had on the later development of SA between mother and child. 


\section{Statement of the Problem}

Hamilton et al. (2019) reported that provision numbers for live births in the United States was $3,788,235$ in 2018 . This is almost four million opportunities for women to bond and create a SA with their infant. However, a SA will not be created out of all the live births. One reason for this is the impact of DV on how the mother views herself as a mother and how she views and reacts to the child (Huth-Bocks et al., 2004; Levendosky, Bogat, \& Huth-Bocks, 2011; Lyon-Ruth et al., 2005). Levendosky, Bogat, Huth-Bocks, Rosenblum et al. (2011) among others have found that mothers who experience DV have a higher chance of creating an insecure attachment (IA) with their child. While Theran et al. (2005) found that progress towards the creation of pseudo SA relationship can be made, those who begin with an IA relationship are unable to move towards a true SA relationship. Later in their lives, children who experience an IA with their primary caregiver have grown to be more maladjusted both socially and emotionally when relating to peers and significant others as compared to their peers who experienced a SA throughout childhood (Benoit, 2004).

While some researchers (Huth-Bocks et al., 2011; Levendosky, Bogat, \& HuthBocks, 2011; Malone et al., 2010) have suggested future exploration of interventions postnatally to aid in the development of a SA between mother and child, Theran et al. (2005) has shown that this may develop an attachment that only looks like SA rather than truly being secure. Because of the impact on both mother and child, it appears to be an issue that should be addressed during the early stages of attachment development, shown to be during pregnancy (Félix Teixeira et al., 2016). At the time, there is no research that looks to interventions prior to birth alone to aid in the development of SA. 


\section{Purpose of the Study}

One purpose of this study was to compare the therapy categories (individual therapy, group therapy, a combination of group and individual therapy, or no therapy) and the observable attachment factors (tolerance, acceptance, pleasure in proximity, and competence as a parent). Another purpose of this study was to explore potential predictive roles of demographic factors (race, income, support system, marital status, childhood abuse, and trauma therapy) on attachment. This study aimed to further the understanding of which general category of intervention may assist in the formation of SA between mothers and their infants when the mother had a history of DV and which predictive factors may effect this attachment.

\section{Research Questions}

The following research questions were used for this study:

1. Are there significant mean differences in secure mother-infant attachment (as measured by tolerance, acceptance, pleasure in proximity, and competence as a parent) for the four trauma therapy categories?

a. Are there significant mean differences in tolerance for the four trauma therapy categories?

b. Are there significant mean differences in acceptance for the four trauma therapy categories?

c. Are there significant mean differences in pleasure in proximity for the four trauma therapy categories? 
d. Are there significant mean differences in competence as a parent for the four trauma therapy categories?

2. Are the theoretical covariance matrix and the empirical covariance matrix equal?

a. If the model is consistent, what are the estimated direct, indirect, and total casual effect among the variables?

Figure 1 shows the hypothesized model for Research Question 2. This model hypothesizes that race/ethnicity, size of support system, marital status, income level, and a history of childhood abuse impact attachment between mother and infant directly and through the experience or lack thereof, of trauma therapy.

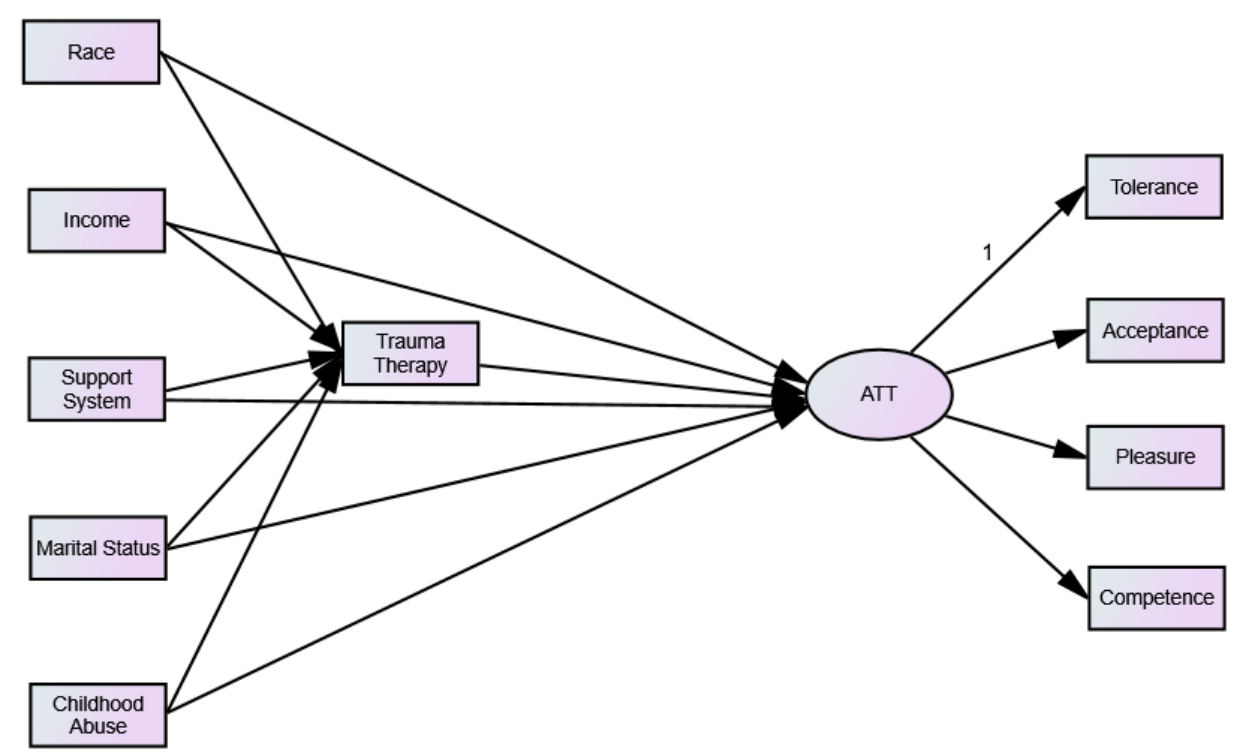

Figure 1. Hypothesized Model 


\section{Significance of the Study}

The topic that was chosen for research was the difference between trauma therapy and SA between mother and infant when the mother had a history of DV. Research, as shown in the literature review, has found that women who experience DV during pregnancy are more likely to view their newborns as themselves (victims who are helpless) or as their abuser (Huth-Bocks et al., 2004; Levendosky et al., 2011; Lyon-Ruth et al., 2005). These views of the newborn, according to these studies, led to one of the three forms of IA. While studies have shown that those who receive counseling after giving birth may be able to move toward what appears externally to be a SA, it appears that a true SA did not develop. This not only affected the mother-infant/child relationship, but also effected the child as they grew into peer and adult attachment relationships.

In examining the difference between trauma therapy prior to giving birth and the formation of mother-infant attachment, it may be possible to find which approach to DV focused trauma therapy has a significant mean difference with SA between mother and infant. With this information, it may be possible to create a trauma focused approach to therapy which aids in the formation of SA between mother and infant. This could have the potential of breaking abuse cycles as the infant grows into their peer and romantic relationships.

\section{Conceptual Framework}

This study was conceptually thought of through the lens of attachment theory. Attachment theory examines the way in which individuals emotionally and physically link to a target individual (Ainsworth \& Bell, 1970; Benoit, 2004; Bowlby, 1969). For 
the study, the link that was examined was between mother and infant. Attachment theory is traditionally thought of as the infant exhibiting specific behaviors to draw the attention of their primary caregiver (typically the mother) in order to form a stronger link to them. However, it is not just the behaviors of the infant that form the link, but also the response of the primary caregiver (Ainsworth et al., 1978; Benoit, 2004; Sroufe, 1988; van Ijzenfoom et al., 1999). If the primary caregiver responds in a consistently loving manner, then it is likely that SA will develop. If the primary caregiver responds in an inconsistent manner or in a way that does not express love, then one of the three forms of IA is likely to develop within that relationship.

In addition to attachment theory, this study was conceptualized through my own observations through my undergraduate internship at an emergency DV and sexual assault shelter that allowed infants and young children to enter with their mothers. During this time, I was able to observe mother-infant and mother-child relationships in which the mother was either overly protective (typically with daughters), overly critical or aggressive (typically with sons), as well as some who showed a SA with their child. The mothers who appeared to have a SA with their children were actively involved in counseling with a staff member (both formally and informally). Those who appeared to have an IA with the children, I observed, tended to speak to staff in order to get something they wanted or to ask if the staff could watch their children so they could go out. They also tended to speak about their experiences with short sentences when asked during the intake interview. The differences between these two "types" of mothers have led to a personal query of the impact of counseling/therapy may have on the attachment that is formed between mother and child in even the mode in which the mother speaks 
with a professional about their experience of DV and affecting the later development of a SA.

With respect to this study, attachment theory was understood through the response of the mother to her infant. The mother's response to her infant, or thoughts of her infant, were measured as a way to understand the attachment that may have formed between the mother and her infant. While previous literature has shown that the mother's response to her infant can correlate with how she views the child, the current study examined if addressing and remediating these views and responses through trauma therapy correlates with a SA style between the participants and their infants.

\section{Definition of Terms}

Domestic Violence: Domestic violence is the use of various tactics in order for one partner to control the other (Department of Justice [DOJ], 2017; National Domestic Violence Hotline [NDVH], n.d.; No More, 2018). In this study, DV will be defined as a male or female partner using various tactics in order to gain and maintain control of a female partner.

Insecure Attachment: Insecure attachment is a form of attachment in which the mother's reaction to thoughts and behaviors in regard to their infant are feelings of depression, tension, anger, fatigue, and confusion. Insecure attachment is made up of three attachment styles: avoidant, anxious, and disorganized (see Ainsworth \& Bell, 1970 and Benoit, 2004 for style definitions).

Secure Attachment: Secure attachment is a form of attachment in which the mother's reaction to thoughts and behaviors in regard to their infant are feelings of joy, contentment, and excitement (see Ainsworth \& Bell, 1970 for traditional style definition). 
Trauma: Trauma is defined as the emotional reaction to past events that continues to be experienced as "unpredictable emotions, flashbacks, strained relationships and even physical symptoms like headaches or nausea" (American Psychological Association [APA], 2018, para. 1). For this study, trauma is focused on the past events of DV that continue or continued to be experienced by the woman after the relationship had ended.

Trauma Therapy: Trauma therapy is a general term for therapy that focuses on past trauma. For this study, the focus of therapy would be DV.

\section{Limitations and Delimitations}

One of the limitations of this study is the ability to generalize the results of this study to the wider target population. Due to sample size, results of this study should be applied to the larger population with caution until further research can be conducted with larger samples. Another limitation was in regard to the self-report measures that were being utilized in the study. Due to the measures being self-report, there was the potential for participants to answer the questions in an untrue manner.

There were a couple delimitations for the study that need to be acknowledged.

The first delimitation: Trauma therapy was not conducted by the research leaving it open for unpredictability on the effectiveness and content that was discussed. The decision to not conduct the trauma therapy during the study was made due to the lack of adequate resources necessary for the research to conduct therapy. Through the demographic information collected, it was hoped to gauge whether or not the participant felt the therapy was effective. A second delimitation was the possibility for participants who have not experienced DV to be part of the study. While efforts were made to screen out 
those who have not experienced DV, the use of online data collection meant that some individuals may have stated that they had experienced DV even though they had not.

\section{Organization of Study}

The study was organized into five chapters. Chapter 1 was an overview of the background of the study, the conceptual framework, and the limitation and delimitations that were found prior to conducting the study. Chapter 2 is a review of the literature in the areas of attachment theory, trauma theory, domestic violence, and how these three areas come together to impact mother-infant and mother-child attachment. Chapter 3 is an overview of the methodology for the study including the sample and the analyses that were used for the study. The results of the study will be discussed in Chapter 4 followed by a discussion of the implications and recommendations within Chapter 5 . 


\section{CHAPTER 2}

\section{LITERATURE REVIEW}

\section{Introduction}

To determine how to help mothers form a more SA with their children, it is important to look at all of the factors that have the potential to play a role in how the mother responds, views, and attaches to others. In this chapter, various factors will be discussed individually and in combination to evaluate their influence on mother-infant attachment. The first area of evaluation is attachment theory followed by trauma theory. Domestic violence will then be discussed as the final individual factor. These three areas will be combined in order to review the literature pertaining to mother-infant attachment when DV and past trauma play a role in the formation of attachment between the mother and her child from pregnancy through childhood.

For this literature review, articles were searched for using Google Scholar and EBSCOHost. Keywords used to search included various combinations of "attachment," "trauma," "mother-infant attachment," "mother-child attachment," and "domestic violence." Articales were chosen based on their relevance to the current research and, in some cases, the year of publication. All articles selected were also required to be peer reviewed and available for full article downloads by the researcher. A few of the articles were found due to their presence in other articles. 


\section{Attachment Theory}

Attachment is a multifaceted construct that cannot have a specific definition, but must be examined individually within each relationship (Ainsworth \& Bell, 1970). However, even with the individuality of attachment, theorists have been able to find a common understanding of how to define attachment. Attachment is typically defined as the affectional link between one individual and another target individual demonstrated by specific behaviors that try to increase the level of connection (Ainsworth \& Bell, 1970; Benoit, 2004; Bowlby, 1969). This connection is typically looked at through the relationship between child and parent which examines the behaviors that the child employs to gain a closer attachment to the parent.

In her 2004 article, Benoit describes the four types of attachment: secure, avoidant, resistant, and disorganized. Starting at about six months of age, infants begin to develop the ability to anticipate the type of response they will receive from their parent leading to the development of attachment behaviors and subsequently an attachment type being displayed more often than other types (Ainsworth et al., 1978; Benoit, 2004; Sroufe, 1988; van Ijzendoorn et al., 1999). The behaviors that indicate attachment are typically defined as those that show the child as trying their parent(s) (Ainsworth \& Bell, 1970; Bowbly, 1969). This closeness may be shown as either physical closeness or a closeness in communication (Ainsworth \& Bell, 1970). Examples of this could include moving towards the parent or clinging to them, smiling, crying, or calling out to the parent (Ainsworth \& Bell, 1970; Bowlby, 1969). Parents who respond with love and affection to the child's attachment behaviors may create a more secure environment and therefore and more SA while those who respond with distress or reject their child may 
provide an environment in which an avoidant, resistant, or disorganized attachment behaviors are developed and therefore prompt the growth within those types (Ainsworth \& Bell, 1970; van Ijzendoor et al., 1999). As reported in 1970 by Ainsworth and Bell, it is important to remember that attachment has many factors that must be examined in order to determine an individual's attachment at that stage in their life. While an individual may have one type of attachment in infancy and childhood, expression of different attachment types may be displayed later in life dependent on their lived experiences.

Typically, attachment during infancy and early childhood is between parent and child, but this changes as the child grows. Bowlby (1969) reported that as the child grows into adolescence and adulthood, the targets of attachment start to shift to peers and those that they are attracted to. Bowlby (1969) continued to report that as an individual grows into old age, they are no longer able to attach to those in generations before them, or even within their same generation. This leaves older individuals to then attach to those that are younger than them, such as their grandchildren. These findings show that attachment is not static and may give hope to those that may not have had a SA in the early stages of their life. As they grow, these individuals may be able to form a more SA with others within their age group or in the younger generations.

\section{Mother-Child Attachment}

Mothers with a SA style have been found to be beneficial to the growth of their child in various ways, one of which is the child's development of a SA style (Grossman et al., 2002; von der Lippe et al., 2010). Children with a SA to their parent(s) have been found to be more emotionally responsive, more comfortable with the exploration of their 
own thoughts and feelings, had more open conversations with the parents, have developed high executive functioning in the form of behavior strategies for when they may be experiencing the emotions of sad, angry, or upset, and tend to be overall more engaged in conversations than their peers who developed within an IA environment (Grossmann et al., 2002; Hsiao et al., 2015; von der Lippe et al., 2010). The mother's SA style may allow them to be more sensitive to their child which aids the child's development in exploration of the through and feelings which gives the child more opportunities to express themselves and elaborate on what they had previously said (Behrens et al., 2016; Hsiao et al., 2015).

Unfortunately, SA do not occur in all mother-child relationships. During pregnancy, mothers who are rated as having attachment anxiety are more likely to be worried (Trillingsgaard et al., 2011). Those who are rated with either attachment anxiety or attachment avoidance were both found to have parenting related stress at a higher rate than their peers one year after giving birth (Trillingsgaard et al., 2011). Both of these outcomes could lead to the child's development of an IA style that may lead to the child being emotionally flat, lacking much substance or engagement in conversations or being less organized, incoherent, or exaggerated in their conversations, possibly stating that they have a lack of trust in their mother's parenting behaviors, and an increased likelihood of being diagnosed with Attention Deficit/Hyperactivity Disorder (De Winter et al., 2016; Hsiao et al., 2015; Salari et al., 2017).

While there is a possibility of a mother and child showing IA styles, DiCarlo et al. (2014), have found that if a mother takes parenting classes within her child's first 18 months, there is a chance of changing the attachment style. With training, DiCarlo et al. 
(2014) found that mothers were able to increase the rate of positive maternal responses, such as celebrating, protecting, communicating, and guiding their infant's learning. This in turn increased the amount of communication in their infant which began the cycle of increasing the amount of positive maternal responses displayed by the mother.

\section{Adult Attachment}

Attachment styles within childhood has also been shown to have an effect on an individual's attachment style and relationship satisfaction in adulthood (Pascuzzo et al., 2013; Rodriguez \& Ritchie, 2009; Tillingsgaard et al., 2011). Pascuzzo et al. (2013) found that adolescents with greater insecurity in regard to attachment to their parents and peers may also have higher rate of an anxious attachment in romantic relationships during adulthood. This anxious attachment could also lead to lowered relationship satisfactions within their romantic relationships (Tillingsgaard et al., 2011). However, those who were able to evaluate their relationships with their parents more objectively and create healthy defense mechanisms, were able to form secure relationships and redirect their attachment needs to those who they view as positive and healthy (Pascuzzo et al., 2013; Rodriquez \& Ritchie, 2009).

\section{Trauma Theory}

The APA (2018) has defined trauma as "an emotional response to a terrible event" that has been shown to have long term implications in the form of "unpredictable emotions, flashbacks, strained relationships and even physical symptoms like headaches or nausea" (para. 1). However, the reaction to various events vary widely and are dependent on the individual's personality and psychological state which accounts for how 
the individual may experience present day events with the awareness of what had occurred in the past (Maté, 2003a). Research also shows that behavioral responses are due to the changes that occur in our brain due to experiencing the event that the individual interprets as traumatic (van de Kolk, 2014).

\section{Trauma Theory and Hormone Activation}

It has been found that the trauma an individual experiences has the potential to increase the level of activity for stress hormones such as adrenaline and cortisol (Maté, 2003a; van der Kolk, 2014). These stress hormones, when experienced over a long period of time throughout the individual's life, may create a state of unease when it is not there (Maté, 2003a). With the decrease in the levels of adrenaline and cortisol, an individual may not only feel uneasiness, but may also be led to seek out experiences that would raise the hormone levels in order to feel what they have come to experience as their normal. Maté (2003a) also stated that research has found uncertainty, lack of information, and a loss of control to be factors that could lead to experiencing stress. These three factors are also often found in traumatic events such as relationships where DV is present. Because of this, those who experience a traumatic event, and therefore high levels of stress, may react in what Levine (2015) calls a "kill or be killed" stance (pp. 40-41). This typically is referred to a fight or flight response and results in the individual either fighting against what they are experiencing, or falling into shame and a sense of helplessness. All this prompts the individual to do what it is that they feel they need to do in order to survive. This sense of helplessness, regardless of whether it is real or perceived, has been shown to be a possible trigger and increase activation of stress hormones (Maté, 2003a). The continual activation of adrenaline and cortisol may not just 
have effects on the way that the individual feels about the world around them, but may also have implications on various areas of the brain.

\section{Trauma Theory and the Brain}

Trauma has been shown to not only increase hormone levels, but to also alter areas of the brain that allow the individual to feel alive (van der Kolk, 2014). These changes in the brain have been shown to increase an individual's vigilance and change the evolutionary survival mechanisms that have allowed the human species to survive (Maté, 2003a; van der Kolk, 2014). Due to a possible inability to distinguish or avoid potentially dangerous situations, some individuals repeat experiences within dangerous or stressful environments leading to the brain being in a continuous state of heightened stress as its norm (Maté, 2003a; van der Kolk, 2014). When applied to DV survivors, the alterations that have been made to the brain and the seeming inability to learn from experiences that have been repeated throughout one's life, would appear to explain, partly, the reason that some individuals do one of the following: continue to remain in the violent relationship, move from one violent relationship to another, or forever be on guard for a good relationship to turn violent.

\section{Domestic Violence}

Domestic violence is defined as a pattern of behaviors that are used within a relationship by one partner to gain or maintain control over the other (DOJ, 2017; NDVH, n.d.; No More, 2017). This can be done through physical harm, threats and intimidation, economic control, sexual violence, harassment and stalking in person and digitally, and/or isolation, among many other behaviors that have the potential to all be 
occurring at the same time rather than in individually. Both the DOJ (2017) and the NDVH (n.d.) state that DV can occur within relationships of any race, ethnicity, age, religion, gender, sexual orientation, education level, and financial status. The DOJ (2017) continues by stating that DV does not only affects the two individuals in the relationship, but also those around them including children, family members, friends, and co-workers.

\section{Types of Domestic Violence}

There are six types of DV that are generally acknowledged by the DOJ (2017) and the NDVH (n.d.). These include: (1) physical abuse or the act of physically harming someone; (2) sexual abuse is the act of coercing, attempting to coerce, or forcing a partner into any sexual act; (3) reproductive coercion or the act of interfering with the partners reproductive system and/or choices including the use or pressure, guilt, and/or shame to become pregnant or to end a pregnancy; (4) emotional or psychological abuse which is defined as the tearing down of the partners self-esteem/self-worth; (5) economic abuse or the act of making or attempting to make an individual financially dependent by

maintaining control over financial resources within the relationship; and (6) digital abuse which is the use of technology to harass, stalk, or intimidate a partner which often appears as emotional abuse through the use of text, phone, and/or social media.

\section{Factors Influencing Domestic Violence}

While perpetration of DV is a choice that one makes, there has been research to show factors which could help in priming an individual to be more apt to be violent towards their partner. Some factors in increasing the risk for DV to occur may include a 
lack of resources for victims to leave (Jackson, 2015), family history of DV and/or child abuse (NDVH, n.d.; Scott Tilley et al., 2008), and beliefs of superiority of the part of the perpetrator (NDVH, n.d.; Scott Tilley \& Brackley, 2005).

When speaking about DV as a learned behavior, research typically examines adults who were raised within a home where DV had occurred (NDVH, n.d.; Scott Tilley et al., 2008). These individuals typically witnessed violence, either physical or other, between their parents and may be a survivor of childhood abuse themselves. Adult perpetrators of DV may have also learned these behaviors from friends or pop culture which could lead to the desensitizing, minimizing, and/or justifying violence, the objectification of women, and/or as examples of how to use power over another in order to get what one wants (NDVH, n.d.; Scott Tilley \& Brackley, 2005).

Scott Tilley and colleagues (2008) found that those who are perpetrators of DV may struggle with social isolation, depression, and low self-esteem. This study also found that these individuals may have a hard time trusting those with whom they are in a relationship with. Lack of trust may be a result of past trauma, but likewise has the potential to increase conflict within the relationship.

Conflict in a relationship could be due to any number of problems, just as it is within relationships that do not include DV; however, the difference may be what Scott Tilley et al., (2008) found to be a lack of anger management skills and having aggression towards women being reinforced throughout the individual's lifetime. The use of drugs and/or alcohol combined with conflict in the relationship similarly have the potential to increase the likelihood of someone becoming violent (NDVH, n.d.; Scott Tilley et al., 2008; Subramani et al., 2017). In their experimental study, Subramani et al. (2017) found 
that the likelihood for perpetrating DV increases with alcohol use of those who have a history of problematic drinking and are acutely intoxicated at the time of the conflict.

\section{Beliefs and Attitudes Regarding Domestic Violence}

While there have been advances in knowledge of DV and the factors that influence violence towards a partner, there are still attitudes that impact society's view. One of these beliefs is that woman should leave the relationship as soon as her partner begins to become violent (Jackson, 2015). Unfortunately, services available to women, if they exist at all, are especially scarce for those who live in rural areas, are scarce in the areas where they exist at all (Peek-Asa et al., 2011). The belief that a woman can easily leave an abusive relationship demonstrates a lack of understanding of the dynamics cultivated by DV and the woman's ability to overcome its damage. This is true especially for women of color who, traditionally, have lesser options due to gender, race, and financial status when compared to their white majority counterparts (Jackson, 2015).

For women who try to end the relationship through legal means, they find themselves facing even more attitudes about DV. Farris and Holman (2015) found that within sheriff's departments throughout the United States, there are many sheriffs who believe that DV is a family issue that should be dealt with in the home. Farris and Holman (2015) also found that there are many sheriffs who hold the belief that violence (physical or sexual) was due to something that the woman had done, such as wearing certain clothing, or due to the lack of income, education, or the use of drugs or alcohol within the home. With these beliefs being held by those who are entrusted to uphold the 
law, individuals who are experiencing DV may not have the option to find the legal means to leave the relationship.

Jackson (2015) found that judges and jurors who are responsible for determining the fate of those tried for homicide due to self-defense in a relationship where DV is present, also hold biases that harm the woman and lead to harsher sentencing. Biases that were discussed included a belief that those who wish to leave a relationship may do so whenever they please, that women are inherently docile and therefore it is only someone who is truly dangerous to society who would follow through with homicide, and that because the perpetrator of violence is not there to defend himself, it may have been the woman who was the true perpetrator of violence within the relationship (Jackson, 2015).

\section{Trauma Therapy and Domestic Violence}

There are many forms of trauma therapy; however, it is typically defined as a type of therapy that helps the individual cope with the effects of their traumatic experiences (California Evidence-Based Clearinghouse for Child Welfare, n.d.). This trauma may have occurred at any time during the individual's life and comes in many forms. In regard to the therapy itself, there are guidelines set forth to help professionals in conducting therapy. Substance Abuse and Mental Health Services Administration (2014) shared two sets of mnemonic guidelines for professionals to remember when working in the area of trauma. The first was the three E's: Events, Experience, and Effects. Events are those circumstances that are later remembered as traumatic for the individual. Experience is how the individual views those traumatic events. Effects are the longlasting adverse consequences of the traumatic event(s). The second are the four R's:

Realization, Recognizing, Responding, and Resist Re-traumatization. Realization is in 
regard to understanding how the traumatic events not only impacted the individual, but all those around them as well. Recognizing is for the ability to see the signs of trauma in terms of being able to screen and assess for trauma. Responding is the application of trauma-informed approaches. Lastly, Resist Re-traumatization is to avoid inadvertently creating an environment that may interfere with the individual's ability to grow and overcome their trauma. While one study (Zlotnick et al., 2011) found marginal impact on depression and post-traumatic stress disorder (PTSD) symptoms when using the interpersonal psychotherapy approach with women during pregnancy, other studies have found significant differences with other approaches.

One approached used within DV shelters is the Helping to Overcome PTSD through Empowerment approach (Johnson \& Zlotnick, 2009). This approach is a short term cognitive-behavioral approach focused on stabilization, safety, empowerment, and skills to help manage PTSD symptoms once the woman has left the shelter and is interacting with community programs and resources on their own. In their study, Johnson and Zlotnick (2009) found both significant and clinically meaningful decreases in PTSD and depressive symptoms, loss of personal and social resources, and degree in social impairment with these results lasting up to six months after the women had left the domestic violence shelter.

An approach for individual use not specific to the DV shelter setting is Cognitive Trauma Therapy for Battered Women (CTT-BW; Kubany et al., 2003). This approach is a treatment protocol that combines elements from prolonged exposure and cognitive processing therapy to reduce avoidance and dysfunctional thoughts and beliefs about previous domestic violence experience. This is conducted through a combination of in 
session in-vivo and imagery work as well as homework assignments to be completed in the client's normal environment. Beck et al. (2016) found in their replication study that the use of CTT-BW significantly reduced the levels of PTSD, depression, and anxiety within the sample population. They also found a reduction in negative cognitions, guilt, and shame related to their traumatic history.

A different approach that studied female survivors of DV was completed by Tutty et al. (2016). These researchers looked at the effectiveness of group therapy for women who had a history of DV. The group program that was utilized was the You're Not Alone program which is based on a narrative approach with the goals of recognizing and understand abuse dynamics, taking responsibility for choices that are made, practice in helping the participant begin to trust in their decision-making skills, and help the participant increase their confidence in their ability to create healthy relationships in the future. Tutty et al. (2016) found lower depression and anxiety symptoms and higher selfesteem for those who completed the program when comparing pre- and post-intervention results.

While the above approaches are designed for use within face-to-face sessions, it has been reported that mental health providers may be harder for some individuals to find based on their location (Health Resources \& Services Administration, 2018). One option to combat this was studied by Gary et al. (2015). The use of Telehealth therapy, particularly with prolonged exposure and cognitive processing therapy approaches, helped to decrease PTSD symptoms for women who had experienced DV or sexual assault showing participants were asymptotic by two to three months after their assault and that spontaneous remission of symptoms was moderate. Not only did symptoms of 
PTSD decrease, but the clients reported satisfaction with every part of the telehealth process. This suggests that the previous barriers to providing mental health may for those who are able to participate in telehealth therapy.

\section{Mother-Child Attachment and Domestic Violence}

Understanding attachment, trauma, DV, and trauma therapy individually and in combination are important; however, for this study, it is also important to understand the impact they have when combined. This section will focus on the how these three areas come together to influence the attachment between a mother and her infant beginning inutero. First, the mother's views of herself and her own abilities will be explored with a focus on how childhood attachment, trauma, and current DV has an impact on the way she views her ability to parent her child. This is followed by a review of literature that looks firstly at attachment between mother and fetus or infant and then attachment between mother and young child.

\section{Influences on Perceived Maternal Capability}

\section{Mother's Childhood}

While it has been documented that childhood abuse has many effects on adulthood (see Danese et al., 2009; Dube, et al., 2001; Whitefield et al., 2003; Winnicott, 1987), it is of importance for this study to examine its impact on attachment to one's child. Women who experience child abuse or neglect are more likely than those who did not to experience an unwillingness or inability to properly care for or attach to their child (Levendosky \& Graham-Bermann, 2001; Malone et al., 2010; Maté, 2003b). Malone et al. (2010) reported that this unwillingness may be due to experiencing rejection from 
their own parents which may lead them to having varying and impractical beliefs of their own child. However, it was found by Lyon-ruth et al. (2005) and Winnicott (1987) that it is not the actual abuse that occurred which may result in a lack of ability to properly care for one's child, but how the woman remembers these events and relationships. Those who remember these events by devaluing the target parent or by seeing themselves as intrinsically bad and the reason for the abuse or neglect, may have a higher likelihood of not being able to form a SA in adulthood with others, especially their own children (Levendosky \& Graham-Bermann, 2001; Lyons-Ruth et al., 2005).

\section{Impact of Domestic Violence}

Domestic violence within a relationship has the potential to have a negative impact on the individual being abused, including in how they may view themselves as a parent. Dependent on the mother's personality type, DV may act as a trigger for thoughts that devalue her and her abilities to parent (Huth-Bocks et al., 2004; Lannert et al., 2013).

Conversely, Lannert et al. (2013) found that certain personality traits may actually act as a buffer to the effects of DV allowing the mother to view herself and her child as independent and increasing the odds of have a balanced representation. For those without these traits, DV may have a large impact on the mother's representation of herself and her child. The presences of DV could take energy from the parenting of the child and put it towards her relationship with her partner (Levendosky, Bogat, Huth-Bocks, Rosenblum et al., 2011; Pires de Almeida et al., 2013); a task that has been shown to negatively impact the psychological abilities of the mother (Levendosky \& Graham-Berman, 2001). These women may appear to be nonchalant, detached, and bad-tempered as a means of 
protection from their relationship or as apprehensive, absent-minded, and doubtful due to the relationship (Huth-Bocks et al., 2004; Malone et al., 2010).

\section{Maternal Views of Child}

While women in the United States are pregnant, they are often told stories of how amazing pregnancy is. They are told stories from other mothers fondly remembering the first time they felt their child move or how they couldn't wait for their child to be born. However, when DV is present, women do not always experience these same moments as joyful. Research has found that women who experience DV during their pregnancy may project views of themselves or of their abuser onto the child (Huth-Bocks et al., 2004; Levendosky, Bogat, \& Huth-Bocks, 2011; Lyon-Ruth et al., 2005) which in turn impacted the way that they viewed the child during pregnancy and the fears that they have leading up to the child's birth. In their 2004 study, Huth-Bocks et al. found that while still in an abusive relationship during pregnancy, mothers are already viewing their child through the same lens that they view themselves (ex: anxious, incapable) or as their partners (ex: bad, aggressive, already beating the mother up). These women tended to be rigid in their views and were typically not accepting of new information.

In spite of this, Huth-Bocks et al. (2004) also found that women who had left the relationship prior to their interview showed a balanced view of their pregnancy and child and were looking forward to the arrival of their child. Women who had left the relationship also tended to show more flexibility in their views and were more open to new information compared to those still in the abusive relationship. 


\section{Mother-Infant Attachment}

Studies have shown that there are many factors influencing attachment between a mother and their newborn and the internal representation that the mother has of the infant. These could include whether the mother is a single parent or has a partner, income level, support system of the mother, and mental health, specifically depression symptoms (Huth-Bocks et al., 2011; Theran et al., 2005). Results of these studies show that those who have a support system, an involved partner, positive role models, livable income, and little to no depressive symptoms were able to form a balanced representation of their newborn starting during pregnancy and therefore a SA was able to be formed. The studies also indicate that those who do not have these things, may not have a balanced view of their child during pregnancy, and may have started with an IA with their newborn. Those who began their relationship with their infant with an IA can move to having a more balanced view and SA over time if they are able to gain the support or resources that they may not have had during pregnancy. However, while they may have been able to form a more secure relationship with their infant, Theran et al. (2005) found that the quality of the interactions between the mothers who moved to a balanced view were still different from those who had always had a balanced view of their infant.

In addition to the factors above, there is an area that appears to be influentially dependent on the time that it is experienced: DV. Research has found that mothers who experience DV during pregnancy were found to form an IA with their newborn, with attachment beginning to form during the pregnancy (Huth-Bocks et al., 2004; Theran et al., 2005; Zeanah et al., 1999). This may be due to the distress that is caused in the relationship an not seeing the infant as an independent individual separate from the 
relationship that they may have been conceived in (Huth-Bocks et al., 2011; Stover et al., 2003; Theran et al., 2005). Feelings of guilt, anger, and shame may also influence the mother's internal representation of the infant and therefore set the stage for an insecure relationship to be formed (Lieberman, 1999; Lieberman \& Van Horn, 1998; Theran et al., 2005). In contrast, Huth-Bocks et al. (2011) found that mothers who did not experience DV during pregnancy, but then experienced it after giving birth, were more likely to have a SA to their infant possibly indicating that the mother is more responsive to the threat to safety and welfare of the infant after they are born and have been experienced as an independent being.

\section{Mother-Child Attachment}

Evidence indicates that a number of factors can influence the mother-infant attachment, but this does not necessarily mean that the type of attachment that was formed will continue throughout the child's lifetime. In fact, there are some relationships that are able to move from insecure to secure (Theran et al., 2005) possibly due to the mother being able to work through her own past and/or present trauma and viewing the child as an independent being separate from the trauma that had occurred (Malone et al., 2010). Still, compared to the mother-child relationships that were able to create a SA during the child's infancy, mother-child relationships that move to form a secure relationship still exhibited lower levels of sensitivity and warmth and high levels of disengagement (Theran et al., 2005).

While some mother-child relationships were able to move from insecure to SA, many of them continued with the IA (Levendosky, Bogat, \& Huth-Bocks, 2011; Levendosky, Bogat, Huth-Bocks, Rosenblum et al., 2011; Theran et al., 2005). There are 
several reasons that this may occur. First, if the mother had experienced childhood neglect, they may not be able to recognize that it occurred, may repress the events that they experienced, or they may continue to hold a negative representation of the abuse (Malone et al., 2010; Maté, 2003b). Also, continued abuse in the home, in which the child witnesses, may impact the child's ability to form a SA with their mother (Levendosky, Bogat, Huth-Bocks, Rosenblum et al., 2011; Levendosky \& GrahamBermann, 2001). Levendosky, Bogat, Huth-Bocks, Rosenblum et al. (2001) also found that mothers who have daughters are more likely to stay in a relationship where DV is present than those who have sons, possibly due to wanting to make sure that the son does not use the violent partner as an example for what it is to be a man. Nonetheless, this leaves the daughters at risk for continued exposure to DV within the home and may continue to reinforce the IA with their mother.

\section{Conclusion}

Various researchers have shown the impact that experiencing DV during pregnancy has on the shaping of IA beginning in-utero and continuing throughout the child's life (i.e. Huth-Bocks et al., 2004; Levendosky, Bogat, Huth-Bocks, 2011; Levendosky, Bogat, Huth-Bocks, Rosenblum et al., 2011; Malone et al., 2010; Theran et al., 2005; Zeanah et al., 1999). While some articles note that IA can move towards SA during the course of the child's lifetime (see Theran et al., 2005), the field as a whole has not yet been able to speak as to the potential impact of addressing issues of DV prior to giving birth on the forming of SAs beginning in-utero or during infancy rather than the later formation of pseudo SA in early to late childhood. 
While some of the articles have stated that future research should focus on treatment after the child has been born in order to help in moving the attachment from IA to SA (Huth-Bocks et al., 2011; Levendosky, Bogat, \& Huth-Bocks, 2011; Malone et al., 2010), this appears to be a way to fix a problem after it has already begun. It may instead be more beneficial to intervene prior to the birth of the infant to aid the mother in forming a SA at birth. Not only would this allow for the mother-infant attachment to possibly develop as secure, but it may also aid in the next generation's ability to create SAs in adult relationships and with their own children. This approach to prenatal intervention will be the focus of this study as a way to assess the impact that it may have on setting the foundation for a SA between mothers and their infants when a history of DV is present for the mother. 


\section{CHAPTER 3}

\section{METHODOLOGY}

\section{Introduction}

The following chapter is an overview of the methodology used to collect and analyze the data. This includes an overview of the research design, the total population and sample size as well as the hypotheses. The chapter also includes variable definitions, an overview of the instrument, the data collection procedure, and the data analysis procedure.

\section{Type of Study}

In order to understand the difference between trauma therapy, attachment, and predictor variables, a quantitative, non-experimental design was used. This design includes a comparative design for a comparison between therapy categories, correlational design for observing the predictive role of the demographic factors and trauma therapy within the path analysis model, and a cross-sectional design as this study included a onetime application of the survey used. The constructs for this research were chosen from the theoretical framework of attachment theory in the context of trauma (Marshall \& Frazier, 2019).

According to Leavy (2017) quantitative research is used in order to find relationships through patterns, correlations, or casual relationships between the measured 
variables. A non-experimental design is an empirical analysis of independent variables that cannot be controlled by the researcher (Hoy \& Adams, 2016). For the purpose of this study, the non-experimental design will allow for an analysis of the data to answer the research questions related to the difference between trauma therapy and mother-infant attachment.

\section{Population and Sample}

The population for the study consisted of mothers in the United States who have infants ages six months and younger during the time period in which data was collected. Hamilton et al. (2018) found that there were approximately 3, 853,472 live births in the United States during 2017. With an effect size of .25, power of .95, and alpha of .05, a sample size based on the number of independent and covariate variables used in this study should be at least 401 participants. Data was collected through the data collection service Qualtrics and participants were screened using questions which asked their gender, age, if they had experienced DV, and if they have an infant six months old or

younger. A total of 3,580 individuals entered the survey link distributed by Qualtrics to, at minimum, answer the screening questions. Of the 3,580 individuals who opened the link, 420 completed the entire survey. Of those 420 , four were removed due to being able to move past the screening questions and then stating that they had no children between the ages of zero and six months old in their home. After these participants were removed, the total sample used for this study was 416 .

\section{Hypotheses}

The research hypotheses for this study are: 
1. There is a significant mean difference in secure mother-infant attachment for the four trauma therapy categories.

a. Tolerance produces a significant mean difference between the four trauma therapy categories.

b. Acceptance produces a significant mean difference between the four trauma therapy categories.

c. Pleasure in proximity produces a significant mean difference between the four trauma therapy categories.

d. Competence as a parent produces a significant mean difference between the four trauma therapy categories.

The null hypotheses for this study are:

1. There is no significant mean difference in secure mother-infant attachment for the four trauma therapy categories.

a. Tolerance produces no significant mean difference between the four trauma therapy categories.

b. Acceptance produces no significant mean difference between the four trauma therapy categories.

c. Pleasure in proximity produces no significant mean difference between the four trauma therapy categories.

d. Competence as a parent produces no significant mean difference between the four trauma therapy categories.

2. The theoretical covariance matrix and the empirical covariance matrix are equal. 


\section{Variables Definition}

Attachment: The affectional link from the parent towards the infant. This is a latent variable measured by: tolerance, acceptance, pleasure in proximity, and competence as a parent (Condon \& Corkindale, 1998).

Tolerance: An absence of feelings of anger and hostility towards the baby, an absence of feeling the baby was being deliberately difficult, and feeling generally relaxed during interactions with the infant (Condon \& Corkindale, 1998). This is measured by The Maternal Postnatal Attachment Scale (MPAS) items 1, 2, and 6 (Condon, 2015).

Acceptance: a lack of resentment about the impact of the baby upon parent's lifestyle and not experiencing the baby as a burden (Condon \& Corkindale, 1998). This is measured by MPAS items 15, 16, and 17 (Condon, 2015).

Pleasure in Proximity: A desire for proximity and enjoyment of interaction (Condon \& Corkindale, 1998). This is measured by MPAS items 3, 7, 8, 9, 10, 11, 12, and 13 (Condon, 2015).

Competence as a Parent: A sense of confidence, competence, and satisfaction at being the mother of the baby. Experiences the baby as her own and perceiving herself as being patient in interactions with the baby (Condon \& Corkindale, 1998). This is measured by MPAS items 4, 5, 14, 18, and 19 (Condon, 2015).

Trauma Therapy: Individual or group therapy that focuses on trauma in regard to the experience of DV. Trauma was defined as "an emotional response to a terrible event" that has been shown to have long term implications in the form of "unpredictable emotions, flashbacks, strained relationships and even physical symptoms like headaches or nausea" (APA, 2018, para. 1). Attendance of the type(s) of therapy attended 
(individual, group, or both individual and group) and perceived effectiveness as well as if no therapy was attended were reported by the participant in the demographic section of the survey. Trauma Therapyx 2 represents either attending trauma therapy or not attending trauma therapy. This variable is used for Research Question 2. Trauma Therapyx 4 represents the use of individual therapy, group therapy, combined individual and group therapy, and no therapy. This variable is used for Research Question 1.

Race/Ethnicity: The racial or ethnic group that the participant identifies as being part of as reported by the participant as part of their demographic information. Participants selected either: white/Caucasian, African American/Black, Hispanic/Latina, or Other with the option to type in their racial/ethnic group.

Support System: The number of individuals that the participant identifies as being part of their support system.

Marital Status: Legal marital status of the participant as reported by the participant as part of their demographic information. Participants either selected: married (including separated) and unmarried (including widowed and divorced).

Income Level: The income level reported by the participant as their average yearly income.

Childhood Abuse: A history of childhood abuse experienced by the participant, or lack of a history of childhood abuse.

\section{The Maternal Postnatal Attachment Scale}

One instrument was used in the study in addition to the demographic questionnaire. The MPAS (Condon, 2015) was used in order to measure aspects of attachment. Both of these instruments are discussed in detail below. 
The MPAS was developed in 1998 by Condon and Corkindale as a way to measure attitudes related to aspects of attachment that the parent has towards their infant. Condon and Corkindale (1998) stated that this measure was developed to look beyond the observable behaviors associated with attachment in order to study the cognitive aspects. The MPAS includes 19 self-report items scored on a Likert scale with total raw scores having a potential range from 19 to 95 . Psychometric information in regard to MPAS was reported by Condon and Corkindale (1998). To test both internal consistency and test-retest reliability, the sample population was given the MPAS in their third trimester and postnatally at four-weeks, four-months, and eight-months with a random sample of women tested every two weeks after the four-month administration. Internal consistency was shown to be $.78, .79$, and .78 at the four-week, four-month, and eight-month administrations respectfully. Pearson correlation coefficient was found to be .86 at the $p$ $<.001$ level. Evidence for construct validity was found in the global attachment scores reported at the four-month administration with the measures of depression (-.32), tension (-.37), anger (-.39), fatigue (-.31), and confusion (-.34) on the Profile of Mood States and depression (-.46) and anxiety (-.34) on the Hospital Anxiety Depression Scale. This negative correlation is evidence of validity in that the higher these negative affect states, the lower the attachment the parent has towards the infant; an idea that is also support through theories in the field of attachment.

\section{Data Collection}

Prior to collecting data, Internal Review Board (IRB) approval (Appendix A) was obtained through the Andrews University IRB. After receiving approval from IRB, data collection procedures through Qualtrics took place. Participants responded to screening 
questions in regard to gender, age, age of child(ren), and experiences of DV which was followed by the informed consent (Appendix B) which was followed by the demographic questionnaire and MPAS (Appendix C). In return for their participation in the research, participants received points through the Qualtrics reward system that they are able to collect and exchange for prizes at a later time. Once all of the data had been collected by Qualtrics, it was transferred into an Excel sheet which the research transferred into Statistical Package for Social Sciences (SPSS).

\section{Analysis of the Data}

Once all data was collected, analysis began with looking for missing data. Missing data for income was replaced with 0 while missing data for support system was replaced with 1 . One outlier was found in support system and was compressed.

Data analysis was conducted with the use of SPSS and Analysis of a Moment Structures (AMOS). Descriptive statistics were performed for the demographic information. Analysis of the data also included a one-way multivariate analysis of variance (MANOVA), one-way univariate analysis of variance (ANOVA), post hoc tests, and a path analysis. A MANOVA was used in order to determine the significant mean differences for Research Question 1. If the MANOVA Lambda is significant, an ANOVA and related post hoc tests would be used in order to determine the significant mean differences for the specific measures seen in Research Questions 1a-d. A path analysis was also used to answer Research Question 2.

The first hypothesis to be tested is: There is a significant mean difference in secure mother-infant attachment for the four trauma therapy categories. In order to retain the null, results from the MANOVA would need to show a higher significant mean 
difference between the trauma therapy categories with $p>.05$ (Mertler \& Vannatta Reinhart, 2017; Warner, 2013). The second hypothesis to be tested for Research Question 1a is: Tolerance produces a significant mean difference between the four trauma therapy categories. In order to retain the null, the results from the ANOVA would need to show a higher significant mean difference between the trauma therapy categories with $p>.05$ (Mertler \& Vannatta Reinhart, 2017; Warner, 2013). To retain the null for the hypotheses for Research Questions 1b-d, the same criteria as for Research Question 1a would need to be met for their individual categories. The hypothesis for Research Question 2 to be tested is: The theoretical covariance matrix and the empirical covariance matrix are equal. In order to retain the null, results from the path analysis would need to show that the hypothesized theoretical model is not a good fit as determined by the chisquare and the other fit indices: Goodness of Fit Index (GFI), Normed Fit Index (NFI), Comparative Fit Index (CFI), Root Mean Square Error of Approximation (RMSEA). Fit indices would need: $\mathrm{GFI} \geq .90, \mathrm{NFI} \geq .95$, and $\mathrm{CFI} \geq .95$ and $\mathrm{RMSEA} \leq .06$ (Hooper et al., 2008).

\section{Summary}

This study was designed to look at the significant mean difference between trauma therapy and mother-infant attachment. These variables were measured through a demographic questionnaire and MPAS. Participants were randomly chosen through a convenience sample utilizing Qualtrics participant pool. After data collection was completed, analysis occurred through SPSS and AMOS.

Chapter 4 will look at the results of the demographic distributions, MANOVA, ANOVAs, post-hoc analysis, and path analysis. This will be followed by a discussion of 
the findings as well as implications of the results on practice and future research in Chapter 5. 


\section{CHAPTER 4}

\section{RESULTS}

\section{Introduction}

One purpose of this study was to compare the therapy categories (individual therapy, group therapy, a combination of group and individual therapy, or no therapy) and the observable attachment factors (tolerance, acceptance, pleasure in proximity, and competence as a parent). Another purpose of this study was to explore potential predictive roles of demographic factors (race, income, support system, marital status, childhood abuse, and trauma therapy) on attachment. In this chapter, the sample demographics are described and the results for each question are presented. Statistical analyses included a MANOVA, ANOVAs, post-hoc analysis, and a path analysis. The level of significance was set at $p=.05$.

\section{Description of Sample}

A total of 3,580 individuals clicked on the link to begin the screening questions. Of those, 420 individuals moved through the screening questions and informed consent and completed both the demographic questionnaire and the MPAS. Of these 420, four individuals were removed due to stating that they had zero children in the home ages zero to six months old. In the end, there were 416 participants whose responses were used for data analysis. 
The characteristics most frequently endorsed by participants were: unmarried $(51.7 \%, n=215)$; white/Caucasian $(62 \%, n=258$; heterosexual $(75.5 \%, n=315)$; between the ages of 25 and $44(64.2 \%, n=267)$; with either one or two children $(68.8 \%$, $n=286$ ); the length of her most recent relationship being between 12 and 35 months $(32.9 \%, n=137)$; a yearly income within the poverty range $(61.8 \%, n=257)$; with zero to five individuals in their support system $(73.8 \%, n=307)$; having had experienced abuse in the home as a child $(59.4 \%, n=247)$; and have not attended therapy for DV related problems $(44.5 \%, n=185)$. Of those who did attend some form of therapy for DV related problems, $81.9 \%(n=177)$ stated that they believed it was helpful. A full description of the participants is shown in Table 1.

\section{Observed Variables Description}

Table 2 presents the means or mode and standards deviations for the following variables: Tolerance, Acceptance, Pleasure in Proximity, Competence as a Parent, and Trauma Therapy. The highest mean reported was in Pleasure in Proximity $(M=4.52 ; S D$ $=.794)$ and the lowest was in Acceptance $(M=3.70 ; S D=1.020)$.

\section{Zero-Order Correlations}

The zero-order correlation (Table 3) showed correlations between variables as the following: Moderate correlation between Trauma Therapyx 2 and Tolerance $(r=.114)$. Strong correlation between Trauma Therapyx4 and Trauma Therapyx $2(r=.935)$, Tolerance and Acceptance $(r=.616)$, Tolerance and Pleasure in Proximity $(r=.532)$, Tolerance and Competence as a Parent $(r=.644)$, Acceptance and Pleasure in Proximity 
Table 1

Demographic Information

\begin{tabular}{|c|c|c|}
\hline & $n$ & $\%$ \\
\hline Age & 416 & \\
\hline $18-24$ & 145 & 34.9 \\
\hline $25-44$ & 267 & 64.2 \\
\hline $45-50$ & 4 & 1.0 \\
\hline Total Number of Children & 416 & \\
\hline $1-2$ & 286 & 68.8 \\
\hline $3-5$ & 114 & 27.4 \\
\hline 6 or more & 16 & 3.8 \\
\hline Race & 416 & \\
\hline White/Caucasian & 258 & 62.0 \\
\hline African American/Black & 57 & 13.7 \\
\hline Latina/Hispanic & 79 & 19.0 \\
\hline Other & 22 & 5.3 \\
\hline Sexual Orientation & 416 & \\
\hline Heterosexual & 315 & 75.7 \\
\hline Lesbian & 8 & 1.9 \\
\hline Bisexual & 83 & 20.0 \\
\hline $\begin{array}{l}\text { Other (Pansexual or Not } \\
\text { Indicated) }\end{array}$ & 10 & 2.4 \\
\hline Marital Status & 416 & \\
\hline Married (including separated) & 201 & 48.3 \\
\hline $\begin{array}{l}\text { Unmarried (never married, } \\
\text { widowed, and divorced) }\end{array}$ & 215 & 51.7 \\
\hline $\begin{array}{l}\text { Length of Most Recent } \\
\text { Relationship }\end{array}$ & 416 & \\
\hline 11 months or less & 69 & 16.6 \\
\hline $12-35$ months & 137 & 32.9 \\
\hline $36-71$ months & 119 & 28.6 \\
\hline 72 or more months & 91 & 21.9 \\
\hline Yearly Income & 416 & \\
\hline $0-30,999$ & 257 & 61.8 \\
\hline $31,000-41,999$ & 52 & 12.5 \\
\hline $42,000-125,999$ & 98 & 23.6 \\
\hline $126,000-187,999$ & 1 & 0.2 \\
\hline 188,000 or more & 8 & 1.9 \\
\hline $\begin{array}{l}\text { Number of People in Support } \\
\text { System }\end{array}$ & 416 & \\
\hline $0-5$ & 307 & 73.8 \\
\hline
\end{tabular}


Table 1-con't

\begin{tabular}{|c|c|c|}
\hline & $n$ & $\%$ \\
\hline $6-10$ & 76 & 18.3 \\
\hline 11 or more & 33 & 7.9 \\
\hline $\begin{array}{l}\text { Experience Abuse in the Home } \\
\text { While Growing Up }\end{array}$ & 416 & \\
\hline Yes & 247 & 59.4 \\
\hline No & 169 & 40.6 \\
\hline $\begin{array}{l}\text { Attended Counseling/Therapy } \\
\text { Related to DV }\end{array}$ & 416 & \\
\hline Yes, Individual & 165 & 39.7 \\
\hline Yes, Group & 15 & 3.6 \\
\hline Yes, Individual \& Group & 51 & 12.3 \\
\hline No & 185 & 44.5 \\
\hline $\begin{array}{l}\text { Was Counseling/Therapy Related } \\
\text { to DV Helpful }\end{array}$ & 216 & \\
\hline Yes & 177 & 81.9 \\
\hline No & 39 & 18.1 \\
\hline
\end{tabular}

Table 2

Observed Variable Statistics

\begin{tabular}{lrr}
\hline & $M$ & $S D$ \\
\hline Tolerance & 4.16 & .794 \\
Acceptance & 3.70 & 1.020 \\
Pleasure & 4.52 & .572 \\
Competence & 4.36 & .696 \\
Trauma Therapyx2* & .00 & .498 \\
Trauma Therapy x4* & 3.00 & 1.387 \\
\hline *Mode reported & & \\
\hline
\end{tabular}

$(r=.531)$, Acceptance and Competence as a Parent $(r=.499)$, as well as Pleasure in Proximity and Competence as a Parent $(r=.548)$.

\section{Results by Question}

This section will discuss the results of the following research questions:

1. Are there significant mean differences in secure mother-infant 
Table 3

Zero-Order Correlation

\begin{tabular}{|c|c|c|c|c|c|}
\hline & $\begin{array}{r}\text { Trauma } \\
\text { Therapy } x 2 \\
\end{array}$ & Tolerance & Acceptance & Pleasure & Competence \\
\hline $\begin{array}{l}\text { Trauma } \\
\text { Therapyx } 4\end{array}$ & $.935^{* *}$ & .082 & .068 & .001 & .054 \\
\hline $\begin{array}{l}\text { Trauma } \\
\text { Therapyx } 2\end{array}$ & & $.114^{*}$ & .086 & .051 & .080 \\
\hline Tolerance & & & $.616^{* *}$ & $.532 * *$ & $.644 * *$ \\
\hline Acceptance & & & & $.531 * *$ & $.499 * *$ \\
\hline Pleasure & & & & & $.548^{* *}$ \\
\hline
\end{tabular}

attachment (as measured by tolerance, acceptance, pleasure in

proximity, and competence as a parent) for the four trauma therapy categories?

a. Are there significant mean differences in tolerance for the four trauma therapy categories?

b. Are there significant mean differences in acceptance for the four trauma therapy categories?

c. Are there significant mean differences in pleasure in proximity for the four trauma therapy categories?

d. Are there significant mean differences in competence as a parent for the four trauma therapy categories?

2. Are the theoretical covariance matrix and the empirical covariance matrix equal?

a. If the model is consistent, what are the estimated direct, indirect, and total casual effect among the variables? 


\section{Question 1}

A MANOVA was conducted in order to determine if there were significant mean differences in the Attachment variables of Tolerance, Acceptance, Pleasure in Proximity, and Competence as a Parent and attending Individual Therapy, Group Therapy, Combined Individual and Group Therapy, or No Therapy.

A MANOVA was conducted to determine Trauma Therapy category differences in Tolerance, Acceptance, Pleasure in Proximity, and Competence as a Parent (see Appendix D for tables). The MANOVA results show a marginally significant differences among the Trauma Therapy categories on the dependent variables [Wilk's $\lambda=.952, F$ $(12,1082)=1.708, p=.060$, partial $\left.\eta^{2}=.016\right]$. An ANOVA was conducted for each of the dependent variables as a follow up test to the MANOVA. Univariate analysis of variance was conducted (Appendix D) and shows that individually, Therapy had a significant effect on Tolerance $\left[F(3,412)=3.794, p=.010 ;\right.$ partial $\left.\eta^{2}=.027\right]$, Pleasure in Proximity $\left[F(3,412)=1.102, p=.017\right.$; partial $\left.\eta^{2}=.024\right]$, and Competence as a Parent $\left[F(3,412)=1.886, p=.008 ;\right.$ partial $\left.\eta^{2}=.028\right]$. The Bonferroni post hoc analysis revealed that not attending therapy significantly differs from attending group therapy in terms of Competence as a Parent $(p=.006)$. Table 4 shows the means and standard deviations for Attachment factors by Trauma Therapy category.

\section{Question 2: Hypothesis Testing}

The hypothesis being tested for Research Question 2 is that the theoretical covariance matrix and the empirical covariance matrix are equal. The hypothesized model for attachment (Figure 2) showed a significant chi-aquare of $73.824(d f=30, p=$ .000). This indicates that the model is not a good fit. However, the good fit indices for 
Table 4

Means and Standard Deviations for Attachment Factors by Trauma Therapy Categories

\begin{tabular}{lrrrrrrrr}
\hline & \multicolumn{2}{l}{ Tolerance } & \multicolumn{2}{c}{ Acceptance } & \multicolumn{2}{c}{$\begin{array}{c}\text { Pleasure in } \\
\text { Proximity }\end{array}$} & \multicolumn{2}{c}{$\begin{array}{c}\text { Competence as } \\
\text { a Parent }\end{array}$} \\
\cline { 2 - 10 } $\begin{array}{l}\text { Trauma } \\
\text { Therapy }\end{array}$ & $M$ & $S D$ & $M$ & $S D$ & $M$ & $S D$ & $M$ & $S D$ \\
Category & & & & & & & & \\
\hline Individual & 4.108 & .885 & 3.672 & 1.010 & 4.539 & .594 & 4.342 & .728 \\
Group & 3.729 & .889 & 3.018 & 1.249 & 4.109 & .717 & 3.825 & .930 \\
Combined & 4.027 & .796 & 3.595 & 1.128 & 4.431 & .543 & 4.314 & .667 \\
No Therapy & 4.285 & .674 & 3.801 & .960 & 4.561 & .534 & 4.441 & .636 \\
\hline
\end{tabular}

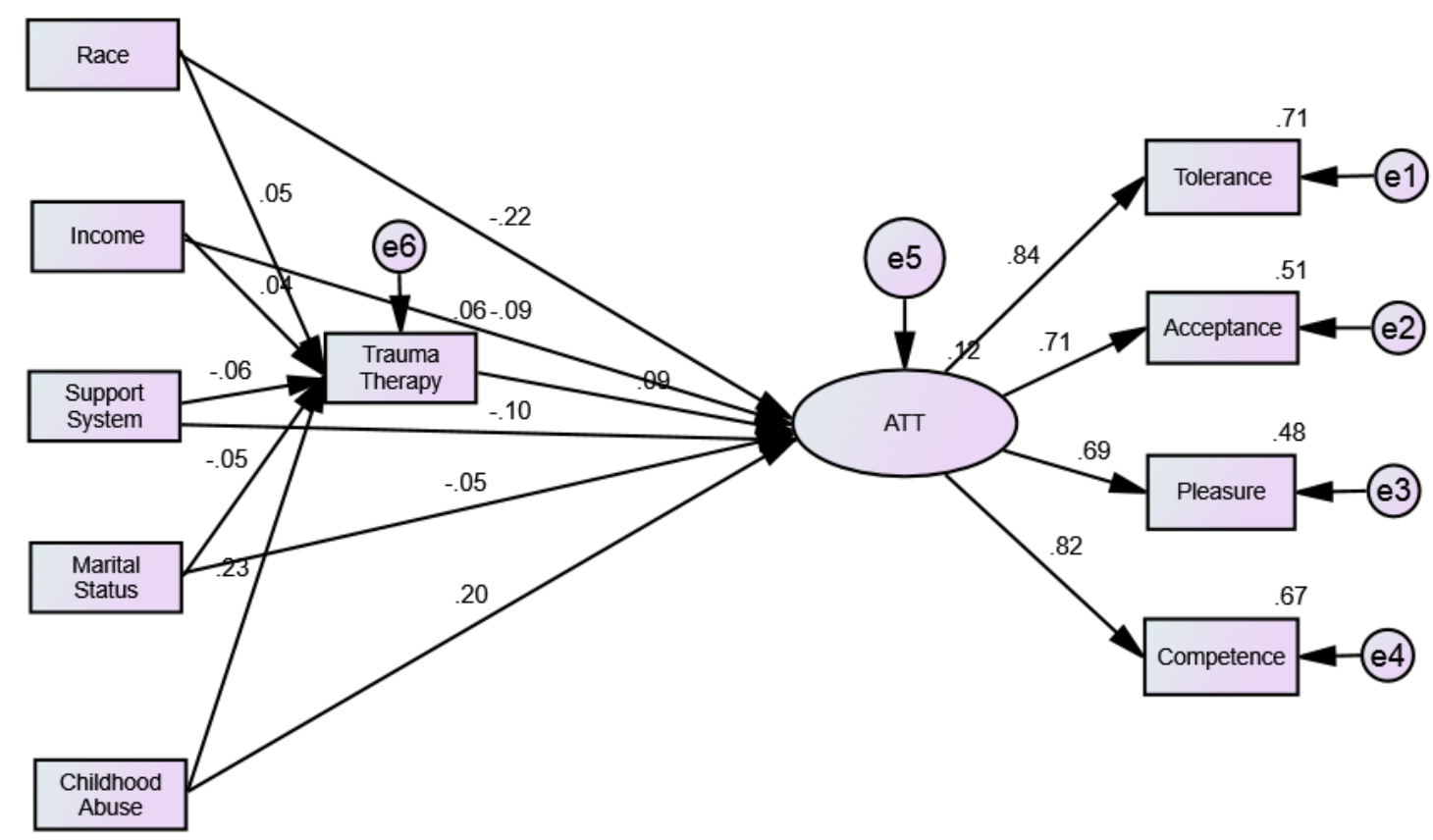

Figure 2. Attachment Model.

the hypothesized model indicates a good fit with GFI $=.968, \mathrm{NFI}=.914, \mathrm{CFI}$

$=.946, \mathrm{RMSEA}=.059$. Based on these results, the hypothesized model was found to be a good fit and explains $12 \%$ of the variance in ATT. 


\section{Intercorrelations Among Variables}

A confirmatory factor analysis for validation and reliability of the MPAS in regard to the current data can be found in Figure 2. These results indicate that tolerance $(\beta=.84 ; p<.001)$ and competence as a parent $(\beta=.82 ; p<.001)$ are strong predictors of attachment while acceptance $(\beta=.71 ; p<.001)$ and pleasure in proximity $(\beta=.69 ; p<$ .001) are moderate predictors. Composite reliability for attachment was found to be .85 . Fornell and Larcker (1981) states that to be reliable, there should be a composite reliability of at least .70 . This composite reliability indicates internal reliability for the data. Convergent validity was found to be .59. Hair et al. (2009) states that to be valid, there should be a convergent validity of at least .50. This convergent validity indicates construct validity for the data.

Table 5 shows the casual effects of the attachment model. Within the model the combination of race, income, support system, marital status, and childhood abuse account for $6 \%$ of the variance in trauma therapy. Childhood abuse is the strongest predictor of trauma therapy $(\beta=.231)$, though it is overall weak. Overall, the model accounted for $12 \%$ of the variance in ATT. Child abuse was the strongest total predictor $(\beta=.224)$ with race having the second highest $(\beta=-.213)$ for ATT, though these predictors have overall weak. Race, income, support system, marital status, and childhood abuse all had an indirect effect on ATT. Childhood abuse had the highest indirect effect on ATT $(\beta=$ .022), thought still overall weak.

Table 6 shows the standardized coefficients in the attachment model. Childhood abuse had a weak statistically significant direct effect on trauma therapy $(\beta=.231, p$ $<.001)$. Race $(\beta=-.218, p<.001)$, childhood abuse $(\beta=.202, p<.001)$, and support 
Table 5

Summary of Casual Effects of the Attachment Model

\begin{tabular}{llrrr}
\hline & & \multicolumn{3}{c}{ Casual Effects } \\
\cline { 2 - 5 } Outcome & Determinant & Direct & Indirect & Total \\
\hline Trauma Therapy & Race & .048 & -- & .048 \\
$\left(R^{2}=.06\right)$ & Income & .041 & -- & .041 \\
& Support System & -.060 & -- & -.060 \\
& Marital Status & -.049 & -- & -.049 \\
& Childhood Abuse** & .231 & -- & .231 \\
ATT & Trauma Therapy & .094 & -- & .094 \\
$\left(R^{2}=.12\right)$ & Race** & -.218 & .005 & -.213 \\
& Income & -.087 & .004 & -.083 \\
& Support System* & -.099 & -.006 & -.105 \\
& Marital Status & -.049 & -.005 & -.054 \\
& Childhood Abuse** & .202 & .022 & .224 \\
\hline$* p<.05$ & & & & \\
$* * p<.001$ & & & & \\
\hline
\end{tabular}

Table 6

Raw and Standardized Coefficients for the Attachment Model

\begin{tabular}{|c|c|c|c|c|}
\hline & $b$ & $S E$ & $\beta$ & $p$ \\
\hline Trauma Therapy $\leftarrow$ Race & .049 & .049 & .048 & .312 \\
\hline Trauma Therapy $\leftarrow$ Income & .000 & .000 & .041 & .386 \\
\hline Trauma Therapy $\leftarrow$ Support System & -.001 & .001 & -.060 & .207 \\
\hline Trauma Therapy $\leftarrow$ Marital Status & -.048 & .047 & -.049 & .307 \\
\hline Trauma Therapy $\leftarrow$ Childhood Abuse & .234 & .048 & .231 & $<.001$ \\
\hline ATT $\leftarrow$ Trauma Therapy & .126 & .069 & .094 & .069 \\
\hline ATT $\leftarrow$ Race & -.300 & .069 & -.218 & $<.001$ \\
\hline $\mathrm{ATT} \leftarrow$ Income & .000 & .000 & -.087 & .080 \\
\hline ATT $\leftarrow$ Support System & -.003 & .002 & -.099 & .047 \\
\hline ATT $\leftarrow$ Marital Status & -.065 & .067 & -.049 & .331 \\
\hline ATT $\leftarrow$ Childhood Abuse & .274 & .070 & .202 & $<.001$ \\
\hline
\end{tabular}

system $(\beta=-.099, p=.047)$ all had weak statistically significant $(p \leq .05)$ direct effects on ATT. In addition to this, trauma therapy had a weak moderately significant direct effect on $\operatorname{ATT}(\beta=.094, p=.069)$. 


\section{Summary of Findings}

A MANOVA was conducted in order to determine if there were significant mean differences in the Attachment variables of Tolerance, Acceptance, Pleasure in Proximity, and Competence as a Parent and attending Individual, Group, Combined Individual and Group, or No Therapy. Results of the MANOVA show an overall marginally significant difference among the Trauma Therapy categories on the dependent variables. However, when looking at the variables individually, Therapy had a significant effect on Tolerance, Pleasure in Proximity, and Competence as a Parent. The Bonferroni post hoc analysis showed that in terms of Competence as a Parent, not attending therapy significantly differs from attending group therapy alone.

A path-analysis was conducted to understand if the theoretical covariance matric and the empirical covariance matrix were equal. The hypothesized model for this study statistically fit in regard to the good fit indices. Based on these results, the hypothesized model was found to be a good fit and explains $12 \%$ of the variance in ATT. Race $(\beta=-$ $.218, p<.001)$, childhood abuse $(\beta=.202, p<.001)$, and support system $(\beta=-.99, p=$

.047) were all weak statistically significant direct predictors of ATT. In addition to this, trauma therapy had a weak moderately significant direct effect on ATT $(\beta=.094, p=$ .069). In terms of indirect effect, childhood abuse had a weak indirect effect on ATT $(\beta=$ .022). Within the model, the variance of trauma therapy explained was $6 \%$ with childhood abuse being a weak statistically significant direct predictor $(\beta=.231, p<$ $.001)$. 


\section{CHAPTER 5}

\section{SUMMARY, DISCUSSION, AND IMPLICATIONS}

\section{Introduction}

This chapter will include a summary of the previous four chapters. This will include a brief overview of the problem, a condensed literature review, an overview of the methodology, and the results. The results will be discussed in terms of their relation to the current literature and the implications and recommendations for future research and clinical practice.

\section{Purpose of Study}

With almost four million live births in 2018 (Hamilton et al., 2019), mother-infant attachment is an important aspect of the human experience. This attachment is the first of many for the infant and impacts their future attachment with peers, romantic interests, and their own children (Bowlby, 1969). While a SA is the best outcome, there are many mother-infant attachments that are insecure. Insecure attachments are likely to be formed when the mother has experienced DV given the right environment (Huth-Bocks et al., 2011; Theran et al., 2005). Postnatal parent training has been studied in the past (Theran et al., 2005), but has shown to only change the way in which the attachment looks externally. However, the attachment remains insecure. Because of this, the purpose of this study aimed to further the understanding of which general category of intervention 
may assist in the formation of SA between mothers and their infants when the mother had a history of DV and which predictive factors may affect this attachment.

\section{Summary of Literature}

\section{Attachment}

Attachment is a multifaceted construct that does not have a specific agreed upon definition, but is typically thought of as the affectional link between one individual and their target individual with the goal to increase the level of connection (Ainsworth \& Bell, 1970; Benoit, 2004; Bowlby, 1969). There are four types of attachment: secure, avoidant, resistant, and disorganized (Benoit, 2004) which begin to develop in-utero for the mother and is detectable by the infant by the time they are about six months old (Ainsworth et al., 1978; Benoit, 2004; Sroufe, 1988; van Ijzendoorn et al., 1999).

The attachment developed during infancy, grows and develops to include not only the primary caregiver, but also peers and romantic interests with attachment in old age being directed to those in the younger generations (Bowlby, 1969). In childhood, children with a SA with their primary caregiver tend to be more emotionally responsive, more comfortable with exploring their thoughts and feelings, had more open conversations with their parents, had developed effective strategies for how to deal with feelings of sadness and anger, and were overall more engaged in conversation with their peers developing in an IA environment (Grossmann et al., 2002; Hsiao et al., 2015; von der Lippe et al., 2010). On the other hand, children who developed in an IA environment were more likely to be emotionally flat, lack substance or engagement in conversations, be less organized, incoherent, or exaggerated in their conversations, possibly stat that they do not trust their mother's parenting behaviors, and had an increased likelihood of 
being diagnosed with Attention Deficit/Hyperactivity Disorder (De Winter et al., 2016;

Hsaio et al., 2015; Salari et al., 2017). These aspects of development tend to be consistent when moving into adulthood and could lead to anxious attachment in adult romantic relationships, but could transition to a SA in romantic relationships if the individual views their parents objectively and formed healthy defense mechanisms throughout childhood and adolescents (Pascuzzo et al., 2013; Rodriquez \& Ritchie, 2009; Tillingsgaard et al., 2011).

\section{Trauma Theory, Domestic Violence, and Trauma Therapy}

Trauma is the emotional response to a traumatic event that has long term implications on the day-to-day functioning of the individual (APA, 2018). Various experiences such as flashbacks, unpredictable emotions, and strained relationships, among other symptoms, can make it feel as if the individual is reliving the traumatic events as a present threat rather than something that occurred in the past. These experiences vary widely and may be dependent on personality type, individual interpretation, the levels of hormone activation, or altered areas of the brain (Levine, 2015; Maté, 2003a; van der Kolk, 2014).

In regard to DV, there are six recognized types: physical abuse, sexual abuse, reproductive coercion, emotional or psychological abuse, economic abuse, and digital abuse (DOJ, 2017). Domestic violence has been found to be influenced by a lack of resources for the victim to leave, a family history of DV and/or child abuse, and perpetrator beliefs of superiority (Jackson, 2015; NDVH, n.d.; Scott Tilley \& Brackley, 2005; Scott Tilley et al., 2008). Maté (2003a) and van der Kolk (2014) have found that 
alterations in the brain structure as well as the increase in hormones can lead to an individual not being prepared for another traumatic event (such as another instance of DV) or they are not able to learn from the previous experiences making it harder for the victim to register the violent acts and leave the dangerous situations. These, along with a continued belief that DV is a family matter (Farris \& Holman, 2015) or that the victims will be held accountable for anything bad that they may do in order to leave the abusive relationship (Jackson, 2015) have the potential to lead to IA between a female survivor and her children.

To lessen the continued impact of DV, there have been multiple approaches to counseling that have been developed. In general, these approaches aim to meet the Substance Abuse and Mental Health Services Administration's 2014 guidelines in regard to Events, Experiences, ad Effects as well as Realization, Recognition, Responding, and Resisting Re-traumatization. Specific treatments that have been found to be effective are Helping to Overcome PTSD through Empowerment within shelters (Johnson \& Zlotnick, 2009), individual CTT-BW (Beck et al., 2016), the You're Not Alone program (Tutty et al., 2016), and individual telehealth therapy for women in rural areas (Gary et al., 2015).

\section{Mother-Infant Attachment and Domestic Violence}

The impact that DV has on the mother's ability to respond to various situations has a big impact on the attachment that she has with her infant. First, through experiencing their own abuse/neglect as a child, the way in which they have processed those events and their relationship with their own parents, and/or experiencing thought processes which say they are incapable of being a good mother, the mother may not 
believe that they are capable of parenting their child (Levendosky \& Graham-Bermann, 2001; Lyon-Ruth et al., 2005; Malone et al., 2010; Maté, 2003a; Winnicott, 1987). A history of DV may also lead to the mother viewing her child either as herself (a victim) or as her abuser (Huth-Bocks et al., 2004; Levendosky, Bogat, \& Huth-Bocks, 2011; LyonRuth et al., 2005). This can impact the thoughts and feelings that the mother has about her infant. While trainings are available to help mothers learn how to properly care for their child, and therefore increase their competence, Theran et al. (2005) found that it was only the outward behaviors that shifted to appear as if the mother had a SA with their infant. The inner thoughts/beliefs of the mother remained within the realm of IA.

While DV may negatively impact the attachment between mother and infant, there are factors that could help. Whether the mother is a single mother or has a partner, their income level, the number of individuals in their support system, their mental health (specifically symptoms of depression), when they experienced the DV, and experiences of childhood abuse can all influence the way that mother responds to attachment seeking behaviors (huth-Bocks et al., 2011; Theran et al., 2005; Zeanah et al., 1999).

\section{Methodology}

This study employed a quantitative, non-experimental design. A convenience sample was used and participants were recruited by Qualtrics. All participants were females between the ages of 18 and 50 years old who had at least one child between the ages of zero and six months old and have a history of domestic violence. Participants responded to questions on a demographics questionnaire and completed the MPAS, a self-report measure, to quantify levels of attachment in four areas: tolerance, acceptance, pleasure in proximity, and competence as a parent. The total number of participants used 
in this study after screening and removing participants who did not meet the criteria was 416. The data was analyzed using SPSS and AMOS to conduct a MANOVA, ANOVAs, post-hoc tests, and a path analysis.

\section{Findings and Discussion}

\section{Sample Demographics}

A total of 420 women participated and completed the surveys. Of the 420 , four of the participants were removed for indicating in the screening questions that they did have children between the ages of zero and six months old in their home and then later stating

that they did not have any children in their home. This created a final sample size of 416 participants (see Table 1). The most frequently endorsed characteristics were: unmarried $(51.7 \% ; n=215)$; white/Caucasian $(62 \%, n=258)$; heterosexual $(75.5 \%, n=315)$; between the ages of 25 and $44(65.2 \%, n=267)$; with either one or two children $(68.8 \%$, $n=286$ ); the length of her most recent relationship being between 12 and 35 months $(32.9 \%, n=137)$; a yearly income within the poverty range $(61.8 \%, n=257)$; with zero to five individuals in their support system $(73.8 \%, n=307)$; having had experienced abuse in the home as a child $(59.4 \%, n=247)$; and have not attended therapy for DV related problems $(44.5 \%, n=185)$.

\section{Research Question 1}

The first research question is: Are there significant mean differences in secure mother-infant attachment (as measured by tolerance, acceptance, pleasure in proximity, and competence as a parent) for the four trauma therapy categories? There were also four 
sub-questions to understand if there is a significant mean difference between each of the four measured areas and the four trauma therapy categories.

Results of the MANOVA (Appendix D) showed a marginally significant difference in among the trauma therapy categories on the dependent variables [Wilk's $\lambda=$ $.952, F(12,1082)=1.708, p=.060$, partial $\left.\eta^{2}=.016\right]$. An ANOVA was conducted and showed that individually there was a statistically significant difference for Tolerance, Pleasure in Proximity, and Competence as a Parent (Appendix D). Bonferroni post hoc analysis (Appendix D) showed that not attending therapy significantly differs from attending group therapy when considering competence as a parent. What these results are showing is that there is a small chance that therapy will impact the dependent variables. Within that chance, if competence as a parent is of concern, it may be better to not attend any therapy as opposed to attending group therapy.

These results may be due to the comparisons that can occur within group therapy/group settings. If the mother is already feeling that she is not competent at the tasks required of her to be a parent, it is more likely that she could view herself as less competent after attending a group of other mothers who she believes are doing much better than she is. To understand this better, future research could include pre- and postgroup tests to gather information on how the mother views herself before and after attending group therapy. Another important consideration for this result is that the current study did not separate out group therapy and psychoeducational classes. It is possible that the participants attended a psychoeducational class which may have led to more comparisons and less empathy and support than may have been found in group therapy. To understand this difference, future research could be more specific in asking 
if participants attended traditional group therapy or a psychoeducation class/workshop. Lastly, because there a slight majority of the current population were unmarried, there may have been problems in finding childcare. To address this, there is the potential to use multiple modalities of therapy that include the infant (Leifer et al., 1989; Trad, 1994). This would impact the mother's ability to attend an individual session while benefiting from the techniques of various modalities.

\section{Research Question 2}

The second research question is: Is the model which describes the casual effect among the variables race/ethnicity, size of support system, marital status, income level, history of child abuse, and trauma therapy on attachment consistent with the observed correlation among these variables? This questions also has one sub-question: If the model is consistent, what are the estimated direct, indirect, and total casual effects among the variables? This was hypothesized as the covariance matrix and the empirical covariance matrix are equal.

The attachment model (Figure 2) showed a significant chi-aquare of $73.824(d f=$ $30, p=.000$ ) indicating a poor fit. When looking at the good fit indices there appears to be a good fit: GFI $=.968, \mathrm{NFI}=.914, \mathrm{CFI}=.946, \mathrm{RMSEA}=.059$. The hypothesized model was determined to be a good fit with the overall model explaining $12 \%$ of the variance in ATT. Race $(\beta=-.218, p<.001)$, childhood abuse $(\beta=.202, p<.001)$, and support system $(\beta=-.99, p=.047)$ were all weak statistically significant direct predictors of ATT while trauma therapy was found to be a weak moderately significant predictor ( $\beta$ $=.094, p=.069)$. As for indirect effect, childhood abuse was found to have a weak statistically significant indirect effect on ATT $(\beta=.022)$. Within the model, the variance 
of trauma therapy explained was $6 \%$ with childhood abuse being a weak statistically significant direct predictor $(\beta=.231, p<.001)$. Given the $12 \%$ of variance explained for ATT, there is still a significant amount of unexplained variance within the model. Due to this, it is possible that future researchers might build on this model by including additional variables that may better explain ATT. In this study, results indicate that even though race, childhood abuse, and support system are predictors of ATT, they did not have a strong impact. Previous research has shown that there are many factors that contribute to whether secure or insecure attachment will form (Huth-Bocks et al., 2011; Theran et al., 2005). One of the factors discussed was mental health, specifically depression symptoms. The current study did not gather data on mental health symptoms or diagnoses which could be a stronger predictor of secure or insecure attachment than those factors that were used. Along other factors, Huth-Bocks et al. (2011) and Threan et al. (2005) found that depression symptoms increased the likelihood of IA. More specifically, Easterbrooks et al. (2017) found that, in regard to PSTD symptoms of adolescent mothers, there were alterations in the child's behavior regulation in comparison to those who did not show PSTD symptoms. In addition to general depression symptoms or PTSD symptoms, due to the age of the infants of the participants of this study, it is possible that the mothers could have been experiencing postpartum depression. Gordo et al. (2018) found that in regard to postpartum depression, the higher the depression symptoms, the higher the perceived stress of parenting and lowered sensitivity to the needs to the infant. Thus, future research could build on this model to add depression symptoms, severity, and/or the specific type of depression experienced to understand the impact of these specific mental health symptoms. 


\section{Limitations}

Due to the use of convenience sampling, the results of this study can only be suggested when speaking of the general population as they are not able to be generalized.

The board approach to defining trauma therapy was a limitation of this study. By leaving it more open for interpretation, there is a chance that some participants believed they attended trauma therapy when they may not have.

Limiting participation to those with children ages zero to six months old was another limitation. Over 3,000 individuals opened a link that was sent to those with children between ages zero and one year old and only 420 individuals moving past the screening questions, this shows that there are more individuals who could have added to this research.

One of the limitations is the distribution of the sample within the types of therapy they endorsed. A total of 165 participants reporting they attended individual therapy, 15 attending group, 51 attending a combination of individual and group therapy, and 185 reporting that they did not attend any type of therapy. This large range could impact the MANOVA results and may not represent the full impact of group or combined individual and group therapy while overrepresenting the impact of individual therapy and not attending any type of therapy.

\section{Recommendations}

The following are recommendations for future research as well as clinical practice. 


\section{Recommendations for Future Research}

1. With a basic definition put forward for trauma therapy and the research not conducting the therapy themselves, it was not possible to control for the type of therapy that was conducted. Because of this, future research should be designed so that the researcher/research team conducts the trauma therapy themselves using a specific approach.

2. Future research should include a pre- and post-group test to gather information on how the participant views herself prior to and after attending group therapy

3. Future research should define and separate group therapy and psychoeducational classes/workshops

4. Future research should add additional variables that may better explain attachment, such as depression or other mental health diagnoses and/or symptoms.

5. Future research should include measures of depression symptoms and/or severity to understand the impact of these specific mental health symptoms on attachment.

\section{Recommendations for Practice}

1. While this study found marginally significant differences in the attachment variables, previous studies found that overall, therapy has helped in reducing the effects of DV for the survivors (Beck et al., 2016; Gary et al., 2015; Johnson \& Zlotnick, 2009; Tutty et al., 2016). Due to this, it is recommended that trauma therapy be used for mothers with a history of DV so as to help in 
reducing the long-lasting effects of DV which may help in improving her attachment to her child(ren).

2. Race, childhood abuse, and support system were all found to have a weak, but significant, effect on attachment. For future clinical practice, it is recommended that these be explored within session to understand how the mother's racial/ethnic background, history of child abuse, and size of support system may be impacting their attachment to their child(ren).

\section{Summary}

In summary, this research showed that trauma therapy had only a small impact on the attachment variables. While tolerance, pleasure in proximity, and competence as a parent were all significant within that small impact, it was found that not attending therapy had more of an impact on competence as a parent than attending group therapy alone.

While previous research has indicated that the woman being married with a stable and adequate income are factors in attachment to their child when having experienced domestic violence (Huth-Bocks et al., 2001; Theran et al., 2005; Zeanah et al., 1999), this study indicated that for this population, these factors were not significant. Childhood abuse was found to be a significant factor (Levendosky \& Graham-Bermann, 2001; Malone et al., 2010; Maté, 2003b), but within this study, it had a weak effect, again, contrary to previous research.

Recommendations were presented for both future research and clinical practice. In terms of future research, it was recommended that researchers look towards a larger sample size, conducting the therapy as part of the research, and conducting pre- and post- 
intervention assessments as well as follow-up attachment assessment. In terms of clinical practice, it was recommended that clinicians use a specific form of trauma therapy that they believe would be best suited for their clients as well as exploring how race, child abuse, and support system may impact the mother's attachment to their child(ren). 
APPENDIX A

IRB APPROVAL 
Dear Nicole,

Congratulations! This letter is to advise you that the Institutional Review Board (IRB) has reviewed and approved your IRB application for research involving human subjects entitled: "The Impact of Prenatal Trauma Therapy on MotherInfant Attachment After Maternal History of Domestic Violence" IRB protocol number 19-038 under Expedited category 45 CFR 46.110 (7). Please find attached your letter of approval.

Thank you.

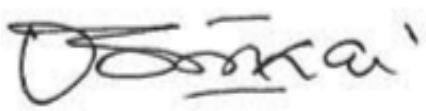

\section{Mordekai Ongo}

Research Integrity \& Compliance Officer

Andrews University

4150 Administration Dr

Berrien Springs, MI 49104-4910

Tel. Office: 269-471-6361

Email: irb@andrews.edu 
APPENDIX B

INFORMED CONSENT 


\section{INFORMED CONSENT}

\section{Purpose}

You are invited to participate in a research project titled The Impact of Prenantal Trauma Therapy on Mother-Infant Attachment After Maternal History of Domestic Violence. The purpose of this research is to determine if therapy or counseling that occurs during pregnancy in regard to problems related to domestic violence impact the attachment that the mother forms with their infant.

\section{Researchers}

This research is being conducted by Nicole Knapp, a doctoral student in the Graduate Psychology \& Counseling Department at Andrews University in Berrien Springs, Michigan. The research is being supervised by Dennis Waite, EdD, LP. Results from this research will be used in Nicole Knapp's dissertation and may be published in professional journals and/or presented at conferences without identifying information about specific participants.

\section{Procedure}

If you choose to participate in this research, you will be asked to complete a demographic questionnaire as well as a survey that include items asking about your thoughts and feelings towards your infant. It will take approximately 10-15 minutes to complete the survey.

\section{Participation}

In order to take part, you must be over 18 years of age and reside in the United States. You must also have given birth to a child within the past 6 months whom you are now raising and have previously experienced domestic violence in an adult relationship. Your participation in this study is completely voluntary. It is your choice whether to participate in the study or not. You may stop at any time.

\section{Risks, Benefits, and Compensation}

Some demographic questions ask about personal history of abuse. This may trigger flashback and memories to various events that you have experienced. If answering these questions triggers these things, please contact your local domestic violence shelter or the National Domestic Violence Hotline at 1-800-799-7233.

By completing these surveys, you may be contributing to a better understanding of how we are able to approach the growth of secure attachments between mother's who have experienced domestic violence and their children. This in turn could lead to less violent relationships for future generations.

By participating in this research, you will be awarded the amount indicated by Qualtrics in the participation invitation. 


\section{Confidentiality}

Your survey responses will be strictly confidential and data from this research will be reported only as a total with all data collected. Your information will be coded and will remain confidential.

\section{Contact Information}

If you have any questions at any time about the survey, your participation in this research, or your rights as a participant, you may contact the principle investigator, Nicole Knapp, at (269) 363-2564 or knappn@andrews.edu. You may also contact her dissertation chair, Dr. Dennis Waite, at (269) 208-2532 or

denniswaite@ phoenixconsultation.com. If you have questions or concerns pertaining to your participation in this study, contact Andrews University IRB at (269) 471-6361 orirb@andrews.edu.

\section{Consent}

Thank you very much for your time! Please start the survey by clicking on the Continue button below. By continuing to the next page, you are giving your consent to participate in the above described research study.

If you wish to not participate in the study, please exit the survey page. 


\section{APPENDIX C}

DEMOGRAPHIC QUESTIONNAIRE \& MPAS 


\section{DEMOGRAPHIC INFORMATION}

Please respond to each of the following demographic items listed below.

Age:

Marital Status:

__ Married (including separated)

Unmarried (never married, widowed, and divorced)

Yearly Income:

Race/Ethnicity:

___ White/Caucasian
$\ldots$ Hispanic/Latina
___ African American/Black
__ Other

Have you attended counseling/therapy for problems related to domestic violence that you have been the victim of?

Yes, Before/During Pregnancy, Individual

Yes, Before/During Pregnancy, Group

Yes, Before/During Pregnancy, Individual and Group

_

If you have attended counseling/therapy for problems related to domestic violence, did you find it helpful?

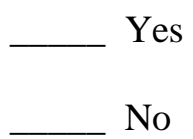

Number of Children:

Length of Most Recent Relationship in Months:

Number of People in Your Support System:

Sexual Orientation:

Heterosexual

Lesbian

Bisexual

Other

Did you experience abuse in the home while growing up?

Yes

No 


\section{MATERNAL POSTNATAL ATTACHMENT SCALE}

These questions are about your thoughts and feelings about your baby. Please tick one box only one answer to each question.

PM1 When I am caring for the baby, I get feelings of annoyance or irritation:

Very Frequently

Frequently

Occasionally

Very rarely

$\square$ Never

PM2 When I am caring for the baby I get feelings that the child is deliberately being difficult or trying to upset me:

Very Frequently

Frequently

Occasionally

$\square$ Very rarely

$\square$ Never

PM3 Over the last two weeks I would describe my feelings for the baby as:

Dislike

No strong feelings towards the baby

Slight affection

Moderate affection

$\square \quad$ Intense affection

PM4 Regarding my overall level of interaction with the baby I:

Feel very guilty that I am not more involved

Feel moderately guilty that I am not more involved

Feel slightly guilty that I am not more involved

$\square$ I don't have any guilty feelings regarding this

PM5 When I interact with the baby I feel:

Very incompetent and lacking in confidence

Moderately incompetent and lacking in confidence

Moderately competent and confident

Very competent and confident

PM6 When I am with the baby I feel tense and anxious:

Very Frequently

Frequently

Occasionally

Almost never 
PM7 When I am with the baby and other people are present, I feel proud of the baby:

$\square$ Very Frequently

Frequently

$\square$ Occasionally

Almost never

PM8 I try to involve myself as much as I possibly can PLAYING with the baby:

This is true

This is untrue

PM9 When I have to leave the baby:

I usually feel rather sad (or it's difficult to leave)

I often feel rather sad (or it's difficult to leave)

I have mixed feelings of both sadness and relief

I often feel rather relieved (and it's easy to leave)

$\square \quad$ I usually feel rather relieved (and it's easy to leave)

PM10 When I am with the baby:

I always get a lot of enjoyment/satisfaction

I frequently get a lot of enjoyment/satisfaction

I occasionally get a lot of enjoyment/satisfaction

I very rarely get a lot of enjoyment/satisfaction

PM11 When I am not with the baby, I find myself thinking about the baby:

Almost all the time

Very frequently

Frequently

$\square$ Occasionally

Not at all

PM12 When I am with the baby:

I usually try to prolong the time I spend with him/her

I usually try to shorten the time I spend with him/her

PM13 When I have been away from the baby for a while and I am about to be with him/her again, I usually feel:

Intense pleasure at the idea

Moderate pleasure at the idea

Mild pleasure at the idea

No feelings at all about the idea

Negative feelings about the idea 
PM14 I now think of the baby as:

Very much my own baby

A bit like my own baby

$\square$ Not yet really my own baby

PM15 Regarding the things that we have had to give up because of the baby:

I find that I resent it quite a lot

$\square \quad$ I find that I resent it a moderate amount

I find that I resent it a bit

I don't resent it at all

PM16 Over the past three months, I have felt that I do not have enough time for myself or to pursue my own interests:

Almost all the time

$\square$ Very frequently

Occasionally

$\square \quad$ Not at all

PM17 Taking care of this baby is a heavy burden of responsibility. I believe this is:

$\square$ Very much so

Somewhat so

Slightly so

Not at all

PM18 I trust my own judgement in deciding what the baby needs:

Almost never

$\square$ Occasionally

$\square$ Most of the time

Almost all the time

PM19 Usually when I am with the baby:

I am very impatient

I am a bit impatient

I I am moderately patient

$\square$ I am extremely patient 


\section{APPENDIX D}

MANOVA TABLES 


\begin{tabular}{|c|c|c|c|c|}
\hline & $\begin{array}{l}\text { Attended Trauma } \\
\text { Therapy }\end{array}$ & $M$ & $S D$ & $n$ \\
\hline \multirow[t]{5}{*}{ Tolerance } & Yes, Individual & 4.1081 & .88452 & 165 \\
\hline & Yes, Group & 3.7289 & .88916 & 15 \\
\hline & Yes, Combined & 4.0268 & .79593 & 51 \\
\hline & No & 4.2852 & .67383 & 185 \\
\hline & Total & 4.1632 & .79400 & 416 \\
\hline \multirow[t]{5}{*}{ Acceptance } & Yes, Individual & 3.6719 & 1.01001 & 165 \\
\hline & Yes, Group & 3.0178 & 1.24861 & 15 \\
\hline & Yes, Combined & 3.5948 & 1.12766 & 51 \\
\hline & No & 3.8009 & .96001 & 185 \\
\hline & Total & 3.6962 & 1.02009 & 416 \\
\hline \multirow[t]{5}{*}{ Pleasure } & Yes, Individual & 4.5389 & .59390 & 165 \\
\hline & Yes, Group & 4.1092 & .71663 & 15 \\
\hline & Yes, Combined & 4.4311 & .54257 & 51 \\
\hline & No & 4.5611 & .53441 & 185 \\
\hline & Total & 4.5201 & .57164 & 416 \\
\hline \multirow[t]{5}{*}{ Competence } & Yes, Individual & 4.3419 & .72809 & 165 \\
\hline & Yes, Group & 3.8253 & .92962 & 15 \\
\hline & Yes, Combined & 4.3141 & .66714 & 51 \\
\hline & No & 4.4411 & .63574 & 185 \\
\hline & Total & 4.3640 & .69649 & 416 \\
\hline
\end{tabular}

Box's Test of Equality of

Covariance Matrices

\begin{tabular}{ll}
\hline Box's M & 44.187 \\
$F$ & 1.398 \\
df1 & 30 \\
df2 & 9828.860 \\
Sig. & .073 \\
\hline
\end{tabular}

Levene's Test of Equality of Error Variances

\begin{tabular}{lllll}
\hline & $F$ & df1 & df2 & Sig. \\
\hline Tolerance & 2.986 & 3 & 412 & .031 \\
Acceptance & 2.322 & 3 & 412 & .075 \\
Pleasure & 1.826 & 3 & 412 & .142 \\
Competence & 3.715 & 3 & 412 & .012 \\
\hline
\end{tabular}




\begin{tabular}{llrrrrrr}
\hline Effect & Value & $F$ & $\begin{array}{c}\text { Hypothesis } \\
\text { df }\end{array}$ & Error df & Sig. & $\begin{array}{c}\text { Partial } \\
\text { Eta } \\
\text { Squared }\end{array}$ \\
\hline Therapy & $\begin{array}{l}\text { Pillai's } \\
\text { Trace } \\
\text { Wilks' }\end{array}$ & .049 & 1.705 & 12.000 & 1233.000 & .060 & .016 \\
& $\begin{array}{l}\text { Lambda } \\
\text { Hotelling's } \\
\text { Trace }\end{array}$ & .952 & 1.708 & 12.000 & 1082.404 & .060 & .016 \\
$\begin{array}{l}\text { Roy's } \\
\text { Largest } \\
\text { Root }\end{array}$ & .030 & 1.710 & 12.000 & 1223.000 & .059 & .017 \\
\hline
\end{tabular}

Tests of Between-Subjects Effects

\begin{tabular}{llrrrrrr}
\hline Source & DV & $\begin{array}{c}\text { Type III } \\
\text { Sum of } \\
\text { Squares }\end{array}$ & df & $\begin{array}{c}\text { Mean } \\
\text { Square }\end{array}$ & $F$ & Sig. & $\begin{array}{c}\text { Eta } \\
\text { Squared }\end{array}$ \\
\hline Therapy & Tolerance & 7.034 & 3 & 2.345 & 3.794 & .010 & .027 \\
& Acceptance & 9.554 & 3 & 3.185 & 3.107 & .026 & .022 \\
& Pleasure & 3.306 & 3 & 1.102 & 3.432 & .017 & .024 \\
& Competence & 5.659 & 3 & 1.886 & 3.972 & .008 & .028 \\
Error & Tolerance & 254.597 & 412 & .618 & & & \\
& Acceptance & 422.286 & 412 & 1.025 & & & \\
& Pleasure & 132.304 & 412 & .321 & & & \\
& Competence & 195.656 & 412 & .475 & & & \\
\hline
\end{tabular}


Multiple Comparisons - Bonferroni

\begin{tabular}{|c|c|c|c|c|c|c|c|}
\hline \multirow[b]{2}{*}{ DV } & \multirow[b]{2}{*}{$\begin{array}{l}\text { (I) Attended } \\
\text { Trauma Therapy }\end{array}$} & \multirow[b]{2}{*}{$\begin{array}{l}\text { (J) Attended } \\
\text { Trauma Therapy }\end{array}$} & \multirow[b]{2}{*}{$\begin{array}{c}\text { Mean } \\
\text { Difference (I-J) }\end{array}$} & \multirow[b]{2}{*}{ Std. Error } & \multirow[b]{2}{*}{ Sig. } & \multicolumn{2}{|c|}{$95 \% \mathrm{CI}$} \\
\hline & & & & & & Lower Bound & Upper Bound \\
\hline \multirow[t]{12}{*}{ Tolerance } & Yes, Individual & Yes, Group & .3792 & .21200 & .446 & -.1828 & .9412 \\
\hline & & Yes, Combined & .0813 & .12594 & 1.000 & -.2526 & .4152 \\
\hline & & No & -.1771 & .08418 & .216 & -.4003 & .0460 \\
\hline & Yes, Group & Yes, Individual & -.3792 & .21200 & .446 & -.9412 & .1828 \\
\hline & & Yes, Combined & -.2979 & .23090 & 1.000 & -.9100 & .3142 \\
\hline & & No & -.5563 & .21104 & .052 & -1.1158 & .0031 \\
\hline & Yes, Combined & Yes, Individual & -.0813 & .12594 & 1.000 & -.4152 & .2526 \\
\hline & & Yes, Group & .2979 & .23090 & 1.000 & -.3142 & .9100 \\
\hline & & No & -.2584 & .12433 & .230 & -.5880 & .0712 \\
\hline & No & Yes, Individual & .1771 & .08418 & .216 & -.0460 & .4003 \\
\hline & & Yes, Group & .5563 & .21104 & .052 & -.0031 & 1.1158 \\
\hline & & Yes, Combined & .2584 & .12433 & .230 & -.0712 & .5880 \\
\hline \multirow[t]{6}{*}{ Acceptance } & Yes, Individual & Yes, Group & .6541 & .27303 & .102 & -.0697 & 1.3779 \\
\hline & & Yes, Combined & .0771 & .16220 & 1.000 & -.3529 & .5072 \\
\hline & & No & -.1290 & .10841 & 1.000 & -.4164 & .1572 \\
\hline & Yes, Group & Yes, Individual & -.6541 & .27303 & .102 & -1.3779 & .0697 \\
\hline & & Yes, Combined & -.5770 & .29737 & .318 & -1.3653 & .2113 \\
\hline & & No & -.7831 & .27179 & .025 & -1.5037 & -.0626 \\
\hline
\end{tabular}




\begin{tabular}{|c|c|c|c|c|c|c|c|}
\hline \multirow[b]{2}{*}{ DV } & \multirow[b]{2}{*}{$\begin{array}{l}\text { (I) Attended } \\
\text { Trauma Therapy }\end{array}$} & \multirow[b]{2}{*}{$\begin{array}{l}\text { (J) Attended } \\
\text { Trauma Therapy }\end{array}$} & \multirow[b]{2}{*}{$\begin{array}{c}\text { Mean } \\
\text { Difference (I-J) }\end{array}$} & \multirow[b]{2}{*}{ Std. Error } & \multirow[b]{2}{*}{ Sig. } & \multicolumn{2}{|c|}{$95 \% \mathrm{CI}$} \\
\hline & & & & & & Lower Bound & Upper Bound \\
\hline \multirow{18}{*}{ Pleasure } & Yes, Combined & Yes, Individual & -.0771 & .16220 & 1.000 & -.5072 & .3529 \\
\hline & & Yes, Group & .5770 & .29737 & .318 & -.2113 & 1.3653 \\
\hline & & No & -.2061 & .16012 & 1.000 & -.6306 & .2184 \\
\hline & No & Yes, Individual & .1290 & .10841 & 1.000 & -.1584 & .4164 \\
\hline & & Yes, Group & .7831 & .27179 & .025 & .0626 & 1.5037 \\
\hline & & Yes, Combined & .2061 & .16012 & 1.000 & -.2184 & .6306 \\
\hline & Yes, Individual & Yes, Group & .4198 & .15282 & .031 & .0246 & .8349 \\
\hline & & Yes, Combined & .1078 & .09079 & 1.000 & -.1329 & .3485 \\
\hline & & No & -.0221 & .06068 & 1.000 & -.1830 & .1387 \\
\hline & Yes, Group & Yes, Individual & -.4289 & .15282 & .031 & -.8349 & -.0246 \\
\hline & & Yes, Combined & -.3220 & .16645 & .323 & -.7632 & .1193 \\
\hline & & No & -.4519 & .15213 & .019 & -.8552 & -.0486 \\
\hline & Yes, Combined & Yes, Individual & -.1078 & .09079 & 1.000 & -.3485 & .1329 \\
\hline & & Yes, Group & .3220 & .16645 & .323 & -.1193 & .7632 \\
\hline & & No & -.1300 & .08962 & .887 & -.3676 & .1076 \\
\hline & No & Yes, Individual & .0221 & .06068 & 1.000 & -.1387 & .1830 \\
\hline & & Yes, Group & .4519 & .15213 & .019 & .0486 & .8552 \\
\hline & & Yes, Combined & .1300 & .08962 & .887 & -.1076 & .3676 \\
\hline \multirow[t]{3}{*}{ Competence } & Yes, Individual & Yes, Group & .5166 & .18584 & .034 & .0239 & 1.0093 \\
\hline & & Yes, Combined & .02788 & .11041 & 1.000 & -.2649 & .3205 \\
\hline & & No & -.0991 & .07379 & 1.000 & -.2948 & .0965 \\
\hline
\end{tabular}




\begin{tabular}{|c|c|c|c|c|c|c|c|}
\hline \multirow[b]{2}{*}{ DV } & \multirow[b]{2}{*}{$\begin{array}{l}\text { (I) Attended } \\
\text { Trauma Therapy }\end{array}$} & \multirow[b]{2}{*}{$\begin{array}{l}\text { (J) Attended } \\
\text { Trauma Therapy }\end{array}$} & \multirow[b]{2}{*}{$\begin{array}{c}\text { Mean } \\
\text { Difference }(\mathrm{I}-\mathrm{J})\end{array}$} & \multirow[b]{2}{*}{$\begin{array}{l}\text { Std. } \\
\text { Error }\end{array}$} & \multirow[b]{2}{*}{ Sig. } & \multicolumn{2}{|c|}{$95 \% \mathrm{CI}$} \\
\hline & & & & & & Lower Bound & $\begin{array}{l}\text { Upper } \\
\text { Bound }\end{array}$ \\
\hline & Yes, Group & Yes, Individual & -.5166 & .18584 & .034 & -1.0093 & -.0239 \\
\hline & & Yes, Combined & -.4888 & .20241 & .097 & -1.0254 & .0478 \\
\hline & & No & $-.6157 * *$ & .18500 & .006 & -1.1062 & -.1253 \\
\hline & Yes, Combined & Yes, Individual & -.0278 & .11041 & 1.000 & -.3205 & .2649 \\
\hline & & Yes, Group & .4888 & .20241 & .097 & -.0478 & 1.0254 \\
\hline & & No & -.1270 & .10899 & 1.000 & -.4159 & .1620 \\
\hline & No & Yes, Individual & .0991 & .07379 & 1.000 & -.0965 & .2948 \\
\hline & & Yes, Group & $.6157 * *$ & .18500 & .006 & .1253 & 1.1062 \\
\hline & & Yes, Combined & .1270 & .10899 & 1.000 & -.1620 & .4159 \\
\hline
\end{tabular}


APPENDIX E

PATH ANALYSIS TABLES 


\section{Hypothesized Model}

Regression Weights: (Group number 1 - Default model)

\begin{tabular}{|c|c|c|c|c|c|}
\hline & Estimate & S.E. & C.R. & $\mathrm{P}$ & Label \\
\hline YesNoTherapy $\leftarrow$ Abuse & .234 & .048 & 4.853 & $* * *$ & \\
\hline YesNoTherapy $\leftarrow$ MaritalStatus & -.048 & 047 & -1.022 & .307 & \\
\hline YesNoTherapy $\leftarrow$ Income & .000 & .000 & .866 & .386 & \\
\hline YesNoTherapy $\leftarrow$ RaceGroup2 & .049 & .049 & 1.010 & .312 & \\
\hline YesNoTherapy $\leftarrow$ Support & -.001 & .001 & -1.263 & 207 & \\
\hline $\mathrm{F} 1 \leftarrow$ RaceGroup2 & -.300 & .069 & -4.340 & $* * *$ & \\
\hline F1 $\leftarrow$ Support & -.003 & .002 & -1.986 & .047 & \\
\hline $\mathrm{F} 1 \leftarrow$ Abuse & .274 & .070 & .3908 & $* * *$ & \\
\hline $\mathrm{F} 1 \leftarrow$ Income & .000 & .000 & -1.750 & .080 & \\
\hline $\mathrm{F} 1 \leftarrow$ YesNoTherapy & .126 & .069 & 1.817 & .069 & \\
\hline $\mathrm{F} 1 \leftarrow$ MaritalStatus & -.065 & .067 & -.972 & .331 & \\
\hline Tolerance $\leftarrow$ F1 & 1.000 & & & & \\
\hline Acceptance $\leftarrow$ F1 & 1.085 & .071 & 15.181 & **** & \\
\hline Pleasure $\leftarrow$ F1 & .591 & .040 & 14.682 & $* * *$ & \\
\hline Competence $\leftarrow$ F1 & .849 & .048 & 17.643 & **** & \\
\hline
\end{tabular}

Standardized Regression Weights: (Group number 1 - Default model)

\begin{tabular}{|c|c|}
\hline & Estimate \\
\hline YesNoTherapy $\leftarrow$ Abuse & .231 \\
\hline YesNoTherapy $\leftarrow$ MaritalStatus & -.049 \\
\hline YesNoTherapy $\leftarrow$ Income & .041 \\
\hline YesNoTherapy $\leftarrow$ RaceGroup2 & .048 \\
\hline YesNoTherapy $\leftarrow$ Support & -.060 \\
\hline $\mathrm{F} 1 \leftarrow$ RaceGroup2 & -.218 \\
\hline $\mathrm{F} 1 \leftarrow$ Support & -.099 \\
\hline $\mathrm{F} 1 \leftarrow$ Abuse & .202 \\
\hline $\mathrm{F} 1 \leftarrow$ Income & -.087 \\
\hline F1 $\leftarrow$ YesNoTherapy & .094 \\
\hline $\mathrm{F} 1 \leftarrow$ MaritalStatus & -.049 \\
\hline Tolerance $\leftarrow$ F1 & .844 \\
\hline Acceptance $\leftarrow$ F1 & .712 \\
\hline Pleasure $\leftarrow$ F1 & .692 \\
\hline Competence $\leftarrow$ F1 & .817 \\
\hline
\end{tabular}


Variances: (Group number 1 - Default model)

\begin{tabular}{|c|c|c|c|c|c|}
\hline & Estimate & S.E. & C.R. & $\mathrm{P}$ & Label \\
\hline Abuse & .241 & .017 & 14.405 & $* * *$ & \\
\hline RaceGroup2 & .236 & .016 & 14.405 & $* * *$ & \\
\hline Support & 422.126 & 29.304 & 14.405 & *** & \\
\hline Income & 4853388288848.390 & 336927133678.519 & 14.405 & **** & \\
\hline MaritalStatus & .250 & .017 & 14.405 & $* * *$ & \\
\hline e6 & .232 & .016 & 14.405 & $* * *$ & \\
\hline e5 & .389 & .040 & 9.791 & $* * *$ & \\
\hline e1 & .180 & .021 & 8.594 & $* * *$ & \\
\hline e2 & .509 & .042 & 12.056 & **** & \\
\hline e3 & .169 & .014 & 12.310 & **** & \\
\hline e4 & .160 & .017 & 9.623 & $* * *$ & \\
\hline
\end{tabular}

Squared Multiple Correlations: (Group number 1 - Default model)

\begin{tabular}{|l|l|}
\hline & Estimate \\
\hline YesNoTherapy & .063 \\
F1 & .125 \\
Competence & .667 \\
Pleasure & .479 \\
Acceptance & .507 \\
Tolerance & .712 \\
\hline
\end{tabular}

Modification Indices (Group number 1 - Default model)

Covariances: (Group number 1 - Default model)

\begin{tabular}{|l|rr|}
\hline & M.I. & Par Change \\
\hline RaceGroup2 <--> MaritralStatus & 5.244 & .027 \\
Abuse <--> MaritalStatus & 6.377 & .030 \\
e3 <--> e4 & 10.508 & .032 \\
e2 <--> e4 & 15.201 & -.067 \\
e1 <--> e3 & 16.789 & -.044 \\
e1 <--> e2 & 8.928 & .056 \\
\hline
\end{tabular}

Regression Weights: (Group number 1 - Default model)

\begin{tabular}{|l|rr|}
\hline & M.I. & Par Change \\
\hline Competence $\leftarrow$ Pleasure & 5.044 & .090 \\
Competence $\leftarrow$ Acceptance & 6.846 & -.059 \\
Tolerance $\leftarrow$ Pleasure & 8.192 & -.127 \\
Tolerance $\leftarrow$ Acceptance & 4.095 & .051 \\
\hline
\end{tabular}




\section{REFERENCE LIST}




\section{REFERENCE LIST}

Ainsworth, M. D., \& Bell, S. M. (1970). Attachment, exploration, and separation: Illustration by the behavior of one-year-olds in a strange situation. Child Development, 41(1), 49-67.

Ainsworth, M. D. S., Blehar, M. D., Waters, E., \& Walls, S. (1978). Patterns of attachment: A psychological study of the strange situation. Erlbaum.

American Psychological Association. (2018). Trauma. http://www.apa.org/topics/trauma/

Beck, J. G., Tran, H. N., Dodson, T. S., Henschel, A. V., Woodward, M. J., \& Eddinger, J. (2016). Cognitive trauma therapy for battered women: Replication and extension. Psychology of Violence 6(3), 368-377.

Behrens, K. Y., Haltigan, J. D., \& Gribneau Bahm, N. I. (2016). Infant attachment, adult attachment, and maternal sensitivity: Revisiting the intergenerational transmission gap. Attachment \& Human Development, 18(4), 337-353.

Benoit, D. (2004). Infant-parent attachment: Definition, types, antecedents, measurement and outcome. Paediatrics \& Child Health, 9(8), 541-545.

Bowlby, J. (1969). Attachment. Attachment and loss: Vol. 1. Loss. Basic Books.

California Evidence-Based Clearinghouse for Child Welfare. (n.d.). Trauma treatment (adult). https://www.cebc4cw.org/topic/trauma-treatment-adult/

Centers for Disease Control and Prevention. (2017). Preventing intimate partner violence. $\mathrm{http}: / / \mathrm{www} . \mathrm{cdc} . \mathrm{gov} / \mathrm{violencepreventtion/pdf/ipv-factsheet.pdf}$

Condon, J. (2015). Maternal postnatal attachment scale [Measurement instrument]. http://hdl.handle.net/2338/35291

Condon, J., \& Corkindale, C. (1998). The assessment of parent-to-infant attachment: Development of a self-report questionnaire instrument. Journal of Reproductive and Infant Psychology, 16(1), 57-76. 
Creswell, J. W., \& Creswell, J. D. (2018). Research design: Qualitative, quantitative, and mixed methods approaches ( $5^{\text {th }}$ ed.). SAGE Publications, Inc.

Danese, A., Moffitt, T. E., Harrington, H., Milne, B. J., Polanczyk, G., Pariante, C. M., Poulton, R., \& Caspi, A. (2009). Adverse childhood experiences and adult risk factors for age-related disease: Depression, inflammation, and clustering of metabolic risk markers. Archives of Pediatrics and Adolescent Medicine, 163(12), 1135-1143.

De Winter, S., Vandevivere, E., Waters, T. E. A., Braet, C., \& Bosmans, G. (2016). Lack of trust in maternal support is associated with negative interpretations of ambiguous maternal behavior. Journal of Child \& Family Studies, 25, 146-151.

Department of Justice. (2017). Domestic violence. http://www.justice.gov/ovw/domesticviolence

DiCarlo, C. F., Onwujuba, C., \& Baumgartner, J. L. (2014). Infant communicative behaviors and maternal responsiveness. Child Youth Care Forum, 43, 195-209.

Dube, S. R., Anda, R. F., Felitti, V. J., Chaoman, D. P., Williamson, D. F., Giles, W. H. (2001). Childhood abuse, household dysfunction, and the risk of attempted suicide throughout the life span: Findings from the adverse childhood experiences study. Journal of the American Medical Association, 286(24), 2089-3096.

Easterbrooks, M. A., Crossman, M. K., Caruso, A., Raskin, M., \& Miranda-Julian C. (2017). Maternal mind-mindedness and toddler behavior problems: The moderating role of maternal trauma and posttraumatic stress. Development and Psychopathology, 29(2017), 1431-1442.

Farris, E. M., \& Holman, M. R. (2015). Public officials and the "private" matter: Attitudes and policies in the county sheriff office regarding violence against women. Social Science Quarterly, 96(4), 1117-1135.

Félix Teixeira, M. I., Martins Marcos Raimundo, F., \& Quintas Antunes, M. C. (2016). Relation between maternal-fetal attachment and gestational age and parental memories. Revista de Enfermagem Referência, 4(8), 85-92.

Fornell, C., \& Larcker, D. F. (1981). Evaluating structural equation models with unobservable variables and measurement error. Journal of Marketing Research, 18(1), 39-50. 
Gordo, L., Oliver-Roig, A., Martinez-Pampliega, A., Iriarte Elejalde, L., FernándezAlcantara, M., \& Richart-Martinez, M. (2018). Parental perception of child vulnerability and parental competence: The role of postnatal depression and parental stress in fathers and mothers. PLOS ONE, 13(8): e0202894 https://doi.org/10.1371/journal.pone.0202894

Gray, M. J., Hassija, C. M, Jaconis, M., Barrett, C., Zheng, P., Steinmetz, S., \& James, T. (2015). Provision of evidence-based therapies to rural survivors of domestic violence and sexual assault via telehealth: Treatment outcomes and clinical training benefits. Training and Education in Professional Psychology, 9(3), 235241.

Grossmann, K., Grossmann, K. E., Fremmer-Bombik, E., Kindler, H., ScheuererEnglisch, H., \& Zimmermann, P. (2002). The uniqueness of the child-father attachment relationship: Fathers' sensitive and challenging play as a pivotal variable in a 16-year longitudinal study. Social Development, 11(3), 301-337.

Hair, J. F., Black, W. C., Babin, B. J., \& Anderson, R. E. (2009). Multivariate data analysis $\left(7^{\text {th }}\right.$ ed.). Pearson.

Hamilton, B. E., Martin, J. A., Osterman, M. J. K., \& Rossen, L. M. (2009, May). Births: Provisional data for 2018. http://www.cdc.gov/nchs/data/vsrr/vsrr-007-508.pdf

Hasiao, C., Kore-Karie, N., Bailey, H., \& Moran, G. (2015). It takes two to talk: Longitudinal associations among infant-mother attachment, maternal attachment representations, and mother-child emotion dialogues. Attachment \& Human Development, 17(1), 43-64.

Health Resources \& Services Administration (2018). HRSA fact sheet. https://data.hrsa.gov/data/fact-sheets

Hooper, D., Coughlan, J., \& Mullen, M. R. (2008). Structural equation modelling: Guidelines for determining model fit. The Electronic Journal of Business Research Methods, 6(1), 53-60.

Hoy, W. K. \& Adams, C. M. (2016). Quantitative research in education: A primer ( $2^{\text {nd }}$ ed.). SAGE Publications, Inc.

Huth-Bocks. A. C., Levendosky, A. A., Theran, S. A., \& Bogat, G. A. (2004). The impact of domestic violence on mothers' prenatal representations of their infants. Infant Mental Health Journal, 25(2), 79-98. 
Huth-Bocks, A. C., Theran, S., A., Levendosky, A. A., \& Bogat, G. A. (2011). A socialcontextual understanding of concordance and discordance between maternal prenatal representations of the infant and infant-mother attachment. Infant Mental Health Journal, 32(4), 405-426.

Jackson, B. L. (2015). No ground on which to stand: Revise stand your ground laws so survivors of domestic violence are no longer incarcerated for defending their lives. Berkeley Journal of Gender, Law, \& Justice, 30(1), 154-181.

Johnson, D. M. \& Zlotnick, C. (2009). HOPE for battered women with PTSD in domestic violence shelters. Professional Psychology: Research and Practice, 40(3), 234241.

Jones, C. A., Parker, T. S., Aheam, M., Mishra, A. K., Verivam, J. N. (2009). Health status and health care access of farm and rural populations. Economic Information Bulletin No 57. United States Department of Agriculture, Economic Research Services.

Kubany, E. S., Hill, E. E., Owens, J. A. (2003). Cognitive trauma therapy for battered women with PTSD: Preliminary findings. Journal of Traumatic Stress, 16, 81-91.

Lanier, C., \& Maume, M. O. (2009). Intimate partner violence and social isolation across the rural/urban divide. Violence Against Woman, 15, 1311-1330.

Lannert, B. K., Levendosky, A. A., Bogat, G. A. (2013). The interaction of maternal personality traits and intimate partner violence as influences on maternal representations. Infant Mental Health Journal, 34(3), 222-233.

Leavy, P. (2017). Research design: Quantitative, qualitative, mixed methods, arts-based, and community-based participatory research approaches. The Guilford Press.

Leifer, M., Croner Wax, L., Leventhal-Belfer, L., Fouchia, A., \& Morrison, M. (1989). The use of multitreatment modalities in early intervention: A quantitative case study. Infant Mental Health Journal, 10(2), 100-116

Levendosky, A. A., Bogat, G. A., \& Huth-Bocks, A. C. (2011). The influence of domestic violence on the development of the attachment relationship between mother and young child. Psychoanalytic Psychology, 28(4), 512-527.

Levendosky, A. A., Bogat, G. A., \& Huth-Bocks, A. C., Rosenblum, K., von Eye, A. (2011). The effects of domestic violence on the stability of attachment from infancy to preschool. Journal of Clinical Child \& Adolescent Psychology, 40(3), 398-410. 
Levendosky, A. A., \& Graham-Bermann. S. A. (2001). Parenting in battered women: The effects of domestic violence on women and their children. Journal of Family Violence, 16(2), 171-192.

Levine, P. A. (2015). Trauma and memory: Brain and body in a search for the living past. A practical guide for understanding and working with traumatic memory. North Atlantic Books.

Liberman, A. F. (1999). Negative maternal attributions: Effects on toddlers' sense of self. Psychoanalytic Inquiry, 19, 737-756.

Lieberman, A. F., \& Van Horn (1998). Attachment, trauma, and domestic violence: Implications for child custody. Child and Adolescent Psychiatric Clinics of North America, 7, 423-443.

Livingston, G. (2018). Stay-at-home moms and dads account for about one-in-five U.S. parents. http://www.pewresearch.org/fact-tank/2018/09/24/stay-at-home-momsand-dads-account-for-about-one-in-five-u-s-parents/

Livingston. G., \& Bialik, K. (2018). 7 facts about U.S. moms. http://www.pewresearch.org/fact-tank/2018/05/10/facts-about-u-s-mothers/

Lyons-Ruth, K., Yellin, C., Melnick, S., \& Atwood, G. (2005). Expanding the concept of unresolved mental states: Hostile/helpless stats of mind on the adult attachment interview are associated with disrupted mother-infant communication and infant disorganization. Development and Psychology, 17, 1-23.

Malone, J. C., Levendosky, A. A., Dayton, C. J., Bogat, G. A. (2010). Understanding the "ghosts in the nursery" of pregnant women experiencing domestic violence: Prenatal maternal representations and histories of childhood maltreatment. Infant Mental Health Journal, 31(4), 432-454.

Marshall, E. M., \& Frazier, P. A. (2019). Understanding posttrauma reactions within an attachment theory framework. Current Opinion in Psychology, 25, 167-171.

Maté, G. (2003a). When the body says no: Exploring the stress-disease connection. John Wiley \& Sons.

Maté, G. (2003a). When the body says no: The cost of hidden stress. Vintage Canada.

Mertler, C. A., \& Vannatta Reinhart, R. (2017). Advanced and multivariate statistical methods: Practical application and interpretation ( $6^{\text {th }}$ ed.). Routledge. 
Murty, S. A., Peek-Asa, C., Zwerling, C., Stromquist, A. M., Burmeister, L. F., Merchant, J. A. (2003). Physical and emotional partner abuse reported by men and women in a rural community. American Journal of Public Health, 93, 10731075.

National Domestic Violence Hotline. (n.d.). Abuse defined. http://www.thehotline.org/isthis-abuse/abuse-defined/

No More. (2018). Know the facts. http://nomore.org/learn/resources/

Pascuzzo, K., Cyr, C., \& Moss, E. (2013). Longitudinal association between adolescent attachment, adult romantic attachment, and emotion regulation strategies.

Attachment \& Human Development, 15(1), 83-103.

Peek-Asa, C., Wallis, A., Harland, K., Beyer, K., Dickey, P., \& Saftlas, A. (2011). Rural disparity in domestic violence prevalence and access to resources. Journal of Women's Health, 20(11), 1743-1749.

Pires de Almeida, C., Sá, E., Cunha, F., \& Pires, E. P. (2013). Violence during pregnancy and its effects on mother-baby relationship during pregnancy. Journal of Reproductive and Infant Psychology, 31(4), 370-380.

Riddell, T., Ford Gilboe, M., \& Leipert, B. (2009). Strategies used by rural women to stop, avoid, or escape from intimate partner violence. Health Care for Women International, 30, 134-159.

Rodriguez, P. D., \& Ritchie, K. L. (2009). Relationship between coping styles and adult attachment styles. Journal of Indiana Academy of the Social Sciences, 13, 131141.

Salari, R., Bohlin, G., Rydell, A-M., \& Thorell, L. B. (2017). Neuropsychological functioning and attachment representations in early school age as predictors of ADHD symptoms in late adolescence. Child Psychiatry \& Human Development, 48, 370-384.

Scott Tilley, D., \& Brackley, M. (2005). Men who batter intimate partners: A grounded theory study of the development of male violence in intimate partner relationships. Issues in Mental Health Nursing, 26(3), 281-297.

Scott Tilley, D., Rugari, S. M., \& Walker, C. A. (2008). Development of violence in men who batter intimate partners: A case study. The Journal of Theory Construction \& Testing 12(1), 28-33. 
Sroufe, L. A. (1988). The role of infant-caregiver attachments in development. In J. Belsky, \& T. Nezworkski (eds.), Clinical implications of attachment (pp.18-38). Erlbaum.

Stover, C. S., Van Horn, P., \& Lieberman, A. F. (2003, April). Parental representations in the play of preschool aged witnesses of marital violence. Poster presented at the Biennial Meeting of the Society for Research in Child Development, Tampa, FL.

Subramani, O. S., Parrott, D. J., \& Eckhardt, C. (2017). Problematic drinking mediates the association between urgency and intimate partner aggression during acute intoxication. Alcoholism: Clinical and Experimental Research, 41(9), 1602-1611.

Substance Abuse and Mental Health Services Administration (2014). SAMGSA's concept of trauma and guidance for a trauma-informed approach. https://store.samhsa.gov/system/files/sma14-4884.pdf

Theran, S. A., Levendosky, A. A., Bogat, G. A., Huth-Bocks, A. C. (2005). Stability and change in mothers' internal representations of their infants over time. Attachment \& Human Development, 7(3), 253-268.

Trad, P. V. (1994). Mother-infant psychotherapy: Integrating techniques of group, family, and individual therapy. International Journal of Group Psychotherapy, 44(1), 53 78 .

Trillingsgaard, T., Elklit, A., Shevlin, M., \& Maimburg, R. D. (2011). Adult attachment at the transition to motherhood: Predicting worry, health care utility and relationship functioning. Journal of Reproductive and Infant Psychology, 29(4), 354-363.

Tutty, L., Babins-Wagner, R., \& Rothery, M. A. (2016). You're not alone: Mental health outcomes in therapy groups for abused women. Journal of Family Violence, 31, 489-497.

van der Kolk, B. (2014). The body keeps the score: Brain, mind, and body in the healing of trauma. Penguin Books.

Van Ijzendoorn, M. H., Schuengel, C., Bakermans-Kranenburg, M. J. (1999). Disorganized attachment in early childhood: Meta-analysis of precursors, concomitants and sequelae. Developmental Psychopathology, 11, 225-249.

von der Lippe, A., Eilertsen, D. E., Hartmann, E., \& Killen, K. (2010). The role of maternal attachment in children's attachment and cognitive executive functioning: A preliminary study. Attachment \& Human Development, 12(5), 429-444. 
Warner, R. M. (2013). Applied statistics: From bivariate through multivariate techniques $\left(2^{\text {nd }}\right.$ ed.). SAGE Publications, Inc.

Whitefield, C. L., Anda, R. F., Dube, S. R., \& Felitti, V. J. (2003). Violent childhood experiences and the risk of intimate partner violence in adults: Assessment in a large health maintenance organization. Journal of Interpersonal Violence, 18(2), 166-185.

Winnicott, D. W. (1987). Babies and their mothers. Addison-Wesley.

Zeanah, C. H., Danis, B., Hirshberg, L., Benoit, D., Miller, D., \& Heller, S. S. (1999). Disorganized attachment associated with partner violence: A research note. Infant Mental Health Journal, 20,77-86.

Zlotnick, C., Capezza, N. M., \& Parker, D. (2011). An interpersonally based intervention for low-income pregnant women with intimate partner violence: A pilot study. Archives of Women's Mental Health, 14, 55-65. 


\section{CURRICULUM VITA}




\section{CURRICULUM VITA}

Name: $\quad$ Nicole D. Knapp

Education: $\quad$ Ph.D., Counseling Psychology, anticipated 2021

Andrews University, Berrien Springs, Michigan

M.A., Clinical Mental Health Counseling, 2016

Andrews University, Berrien Springs, Michigan

B.S., Psychology, 2014

Concentration: Applied Behavioral Analysis

Northern Michigan University, Marquette, Michigan

\section{PROFESSIONAL EXPERIENCE}

2018 - Present $\quad$ Graduate Assistant - Graduate Psychology and Counseling

Andrews University

Berrien Springs, Michigan

$2019-2020$

M.A. Practicum Supervisor

Andrews University

Berrien Springs, Michigan

$2017-2018$

Ph.D. Student Counselor

Andrews University Counseling \& Testing Center

Berrien Springs, Michigan

$2016-2017$

Ph.D. Student Counselor

Andrews Community Counseling Center

Berrien Springs, Michigan

2015 - $2019 \quad$ Dissertation Secretary

Andrews University

Berrien Springs, Michigan

$2015-2016$

M.A. Student Counselor Intern

Men In Crisis

Baroda, Michigan

2015

M.A. Student Counselor

Andrews Community Counseling Center

Berrien Springs, Michigan 
2014-2015 Graduate Assistant - Public Health, Nutrition, \& Wellness Andrews University

Berrien Springs, Michigan

2013 - $2014 \quad$ Psychology Intern

Marquette County Women's Center Harbor House

Marquette, Michigan

\section{PRESENTATIONS}

Fisher, J., Mitchell, D., \& Knapp, N. (2018, March). What to do after a lockdown. Presentation for Andrews University Faculty and Staff, Berrien, Springs, MI.

Knapp, N. (2018, March). Dating violence. Presentation for Andrews University Student Life Tuesday Choice Series, Berrien Springs, MI.

Knapp, N. (2018, January). Understanding \& coping with stress. Presentation for Andrews University Student Life Tuesday Choice Series, Berrien Springs, MI.

Knapp, N. (2017, October). Strengths and purposes for the Good Fit Test. Presentation for Andrews University Student Life Tuesday Choice Series, Berrien Springs, MI.

Knapp, N. (2016, September). Strengths and purposes for the Good Fit Test. Presentation for Andrews University Student Life Tuesday Choice Series, Berrien Springs, MI.

\section{VOLUNTEER EXPERIENCE}

2018 - Present $\quad$ Peer Crisis Support Team Student Leader

2017 - Present $\quad$ M.I.R.R.O.R. Diversity Training Team Member

2016-2018 Peer Crisis Support Team Member

2015 Domestic Violence and Sexual Assault Discussion Panel CoOrganizer 